\title{
Calculation Proposal for the Economic Level of Apparent Losses (ELAL) in a Water Supply System
}

\author{
Francisco J. Arregui ${ }^{1, *} \mathbb{C}$, Ricardo Cobacho ${ }^{1}$, Javier Soriano ${ }^{1}$ and Ruben Jimenez-Redal ${ }^{2}$ (I) \\ 1 ITA-Grupo de Ingeniería y Tecnología del Agua, Dpto. de Ingeniería del Agua y Medio Ambiente, \\ Universitat Politecnica Valencia, Camino de Vera s/n, 46022 Valencia, Spain; rcobacho@ita.upv.es (R.C.); \\ jasool@ita.upv.es (J.S.) \\ 2 Faculty of Engineering, UPV-EHU, 48013 Bilbao, Spain; ruben.jimenez.redal@outlook.com \\ * Correspondence: farregui@ita.upv.es; Tel.: +34-963-879-898
}

Received: 24 October 2018; Accepted: 4 December 2018; Published: 9 December 2018

\begin{abstract}
The manuscript describes a simplified methodology with which to assess the economic level of apparent losses (ELAL) in a water utility. This economic point corresponds to the break-even point for which the marginal benefit of increasing the frequency of the apparent losses' reduction activities equalizes the marginal cost of their implementation. For this calculation, each apparent loss component, as defined by the International Water Association, has been subdivided into two additional categories. These categories have been established depending on how periodic activities conducted by the water utility to reduce apparent losses-namely water meter replacement and customers' connection inspections-may affect their magnitude. It has been found that the ELAL is influenced by intervention costs, the degradation rate of the accuracy of water meters and water tariffs. In addition, this work defines a set of performance indicators to benchmark the apparent loss's performance relative to the minimum achievable and optimum levels of the losses. Finally, two case studies on how the proposed calculation should be applied have been added to the appendices.
\end{abstract}

Keywords: apparent losses; water losses; water meter accuracy, water meter management

\section{Introduction}

The design of effective water loss control and reduction policies has become a crucial aspect of the technical management of any modern water utility [1,2]. Water losses multiply the operational costs of water distribution companies, constrain the revenue and reduce the expansion potential of the water utility to increase the number of clients in the future.

According to their nature, water losses can be classified into two main components: real (physical) losses and apparent (commercial) losses [3]. Real losses comprise of physical leakages in pipes, service connections or reservoirs, as well as other losses occurring during short-duration large pipe bursts. Apparent losses are caused by customer metering inaccuracies [4-6], illegal consumption, and data handling errors [7-9]. Figure 1 summarizes the different components of real and apparent losses as defined by the International Water Association (IWA) water balance.

While real losses are typically more important in terms of volume, apparent losses become similar in magnitude in terms of cost for the water utility $[3,10,11]$. This can be explained considering that the cost to a utility of a cubic meter lost in a pipe is equal to the sum of the production and distribution costs. On the contrary, a cubic meter consumed by a user but not measured reduces the revenue in a quantity equal to the selling price of the last cubic meter of water consumed by that customer.

Among the numerous publications related to real losses, those produced by the Water Loss Specialist Group of the IWA deserve special attention [12]. These works have (i) identified the most significant driving factors of real losses, (ii) modelled the relationship between them and the magnitude 
of water losses and (iii) optimized real loss management strategies. All these publications approach the problem from a practitioner's point of view and are aimed not only at companies owning detailed information about their water network and operation procedures, but also at those systems with limited and poor data quality [13-16].

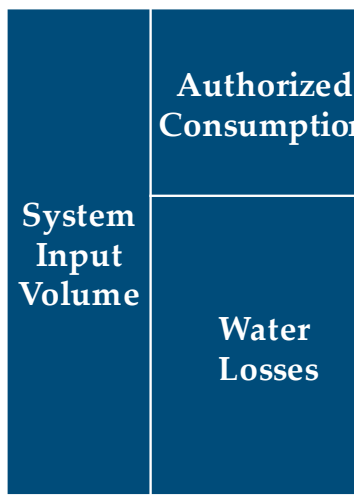

Billed Authorized
Consumption
Unbilled Authorized
Consumption
Apparent Losses
Real Losses

\begin{tabular}{|c|}
\hline Billed Metered Use \\
Billed Unmetered Use \\
Unbilled Metered Use \\
Unbilled Unmetered Use \\
\hline Customer Metering Inaccuracies \\
\hline Unauthorized Consumption \\
\hline Data-Handling Errors \\
\hline Leakage on Transmission and Distribution Mains \\
\hline Leakage and overflows at utiliy's Storage Tanks \\
\hline Leakage on Service Connections
\end{tabular}

Figure 1. The real and apparent loss components [3].

In the case of apparent losses, there are several publications related to their quantification and technical management. These publications approach the topic either providing a brief overview of it $[7,8,17]$ or, alternatively, by dealing with specific issues: measuring errors in intermittent water supply systems [18], numerical models to estimate apparent losses [19], measuring errors caused by the presence of roof tanks [20], analysis of water meters accuracy [21], etc. None of these works have managed to standardize the terminology, the performance indicators to be used, the methodology to quantify the various components or to establish the optimum level of apparent losses as a whole. Taking into account that apparent losses can reach up to $30 \%$ of total losses [3,22] in terms of volume and $50 \%$ in terms of cost, it is unfortunate that up to date there has not been a widely accepted methodology that approaches the issue of finding the economic level of apparent losses from an equivalent perspective to the one used for real losses. Such an approach would be highly valuable as a preliminary strategy for water utilities with limited or no experience on the subject and could serve as daily work guidelines for utilities with some background. This is the aim of this paper, to present a standardized, simplified and well-structured methodology, similar to the one used for real losses to estimate the optimum level of apparent losses.

For this exercise, a detailed component analysis of apparent losses (Figure 1), as described by Lambert et al. [6], is conducted in Section 2. The first component, and probably the most important one for most utilities, is associated with water meter inaccuracies. The reason is that even in a best-case scenario when meters have been recently installed, there is an unavoidable measuring error intrinsic to the meter technology used. Furthermore, as meters age and their mechanical parts wear out, their metrological characteristics degrade and measuring inaccuracies increase [23]. The resulting apparent losses (meters under-registration) will depend on the working conditions of the meter and also on the customers' consumption profile [24]. The second component of apparent losses is related to illegal consumption caused by meter tampering or the presence of illegal connections. As further explained in this manuscript, a portion of illegal consumption will always be present no matter the strength of the utility policies to avoid illegal uses, whereas there will be another portion that will constantly increase over time if the water utility does not implement effective corrective measures. Finally, the third component of apparent losses is caused by the data-handling procedures used by the water company to calculate water consumption volumes from the customers. In general, this component is small in modern water utilities but may have a significant magnitude in those systems without proper quality control procedures.

In order to implement the proposed methodology, these components of apparent losses are further split into two categories: (i) the first one is independent of the reduction and control activities 
conducted by the water utility (intervention independent) and (ii) the second one is dependent on the frequency of the activities carried out to reduce apparent losses (intervention dependent).

Similar to real losses, a key feature of apparent losses is that they tend to increase over time if the water utility does not take appropriate measures. Therefore, management policies for apparent losses can also be classified as active or passive, depending on whether or not they include regular corrective measures aimed to reduce their magnitude. Passive policies will only resolve large and reported meter failures or illegal uses, paying no attention to those little-hidden flaws that build up significantly in the long term. On the contrary, active policies plan and schedule regular interventions, namely water meter replacements and customers' connections inspections to keep apparent losses under control. Section 3 defines the main parameters related to an active policy, paying particular attention to the various costs associated with its implementation.

Many of the works by IWA and AWWA [10,25-28] highlight the existence of (i) an unavoidable level of losses below which it is extremely difficult to achieve further reductions; (ii) an economic level of losses for which the costs of reducing water losses are balanced with the benefit of recovering additional volumes (Figure 2). However, none of these documents defines a methodology to estimate the actual value of such an economic level of apparent losses given the specific conditions of the water utility $[29,30]$. The calculation of the Economic Level of Apparent Losses (ELAL), as well as other related variables, is developed in Section 4 by balancing the resources dedicated to regular interventions (costs) and the benefits they generate (savings). Additionally, a proposal of three performance indicators for apparent losses is presented in Section 5. Finally, and in order to better illustrate the methodology, Appendices A and B develop two case studies. The first one corresponds to an extremely simple case, representative of utilities with very limited data, while the second conducts a more detailed calculation differentiating by the meter and customer types.
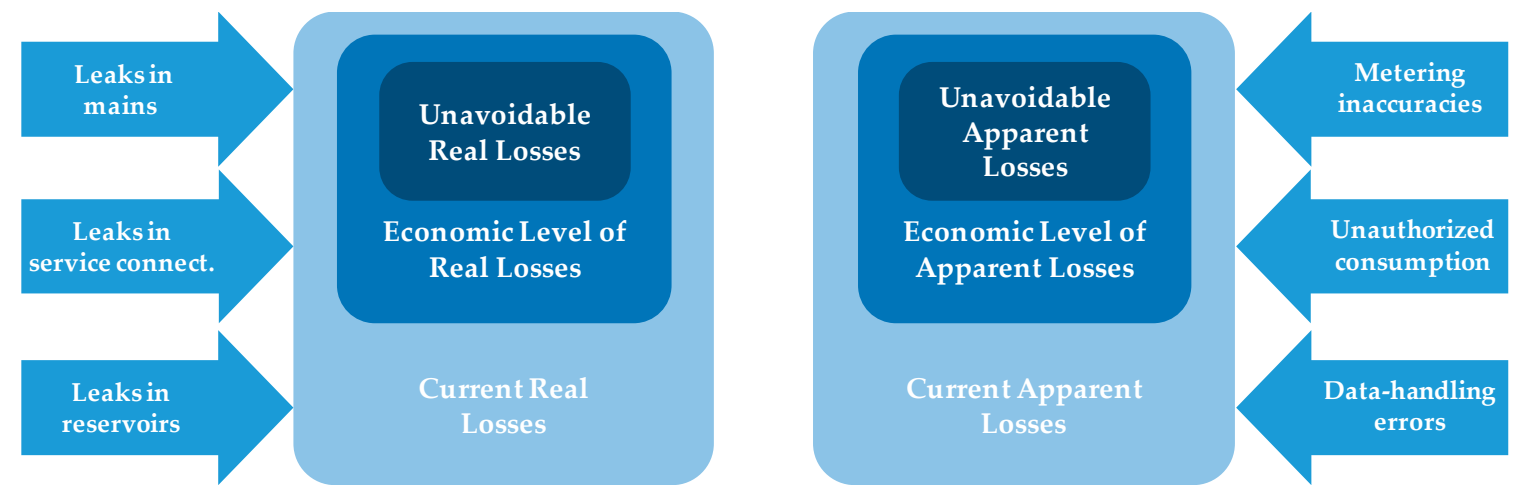

Figure 2. The levels of water losses [6].

\section{Components of Apparent Losses}

Apparent losses have been classified depending on the influence that a potential intervention from the water company may have on their magnitude. Such interventions may also be of two kinds: meter replacement to reduce meter accuracy issues or field inspection to mitigate illegal consumption volumes. Following this criteria, two main categories are defined:

- Intervention independent apparent losses. This category is related to the unavoidable level of losses in a system, no matter the number and frequency of the interventions regularly carried out. These losses could only be reduced if there is a substantial change in an essential element of the system (water metering technology, installation conditions of the meters, a variation of water meter suppliers quality, etc.), but they would not be affected if, for example, customers' meters are replaced more frequently. When expressed in annual terms, this category is called the Intervention Independent Annual Apparent Losses (IIAAL, in $\mathrm{m}^{3} /$ year). 
- Intervention dependent apparent losses. This category is related to the amount of losses that depends on the intervention policies carried out by the water company and grows when interventions are delayed over time. On the contrary, more frequent interventions requiring greater investments by the utility lead to smaller volumes of apparent losses. When expressed in annual terms, this category is called the Intervention Dependent Annual Apparent Losses (IDAAL, in $\mathrm{m}^{3} /$ year).

As summarized in Figure 3, each category can be subdivided further into different apparent loss components, all of them expressed in annual terms $\left(\mathrm{m}^{3} /\right.$ year).

\begin{tabular}{|c|c|c|}
\hline \multirow{3}{*}{$\begin{array}{l}\text { Current Annual } \\
\text { Apparent Losses } \\
\quad \text { (CAAL) }\end{array}$} & $\begin{array}{l}\text { Intervention } \\
\text { Independent Annual } \\
\text { Apparent Losses } \\
\text { (IIAAL) }\end{array}$ & $\begin{array}{l}\text { IIAAL due to Meter Inaccuracies (IIAAL } \\
\text { IIAAS })\end{array}$ \\
\hline & & IIAAL due to Data Handling Errors (IIAAL $\left.\mathrm{L}_{\mathrm{DH}}\right)$ \\
\hline & $\begin{array}{l}\text { Intervention Dependent } \\
\text { Annual Apparent } \\
\text { Losses } \\
\text { (IDAAL) }\end{array}$ & $\begin{array}{l}\text { IDAAL due to Meter Inaccuracies (IDAAL }{ }_{\mathrm{MES}} \text { ) } \\
\text { IDAAL due to Illegal Connections (IDAAL }{ }_{\mathrm{ILL}} \text { ) }\end{array}$ \\
\hline
\end{tabular}

Figure 3. The apparent water losses components by intervention dependency category.

\subsection{IIAAL-Intervention Independent Annual Apparent Losses}

The IIAAL includes the following components:

- Unavoidable measuring errors (IIAAL $L_{M E S}$ ), which are associated with the minimum (initial) measuring the error of brand new water meters. The magnitude of this term depends not only on the metering technology but also on the consumption characteristics of the users, as defined by their water consumption flow rate probability distribution function [24].

This component also includes a contribution from the number of meters damaged or not working because of a manufacturing defect or an incorrect installation. These additional losses occur regardless of the manufacturer or meter technology employed as there is always a percentage of procured water meters failing after installation. The number of defective meters depends, among other factors, on their working principle, manufacturing quality, installation procedures or working conditions in the field. The amount of water loss in a meter failure event is a function of (i) the average time between failure and repair/replacement of the meter and (ii) the rate of consumption of the customer.

- Unavoidable illegal uses of water $\left(I I A A L_{I L L}\right)$. Even if great effort and resources are put in place to avoid the illegal uses of water, there will always be a minimum volume of water taken from the system without the company's knowledge or authorization. This minimum volume is mainly related to local socio-cultural and economic conditions.

- Systematic data handling errors $\left(I I A A L_{D H}\right)$. This component is typically caused by data manipulations performed by the water utility when actual meter readings are not available or are noticeably wrong. Frequently, it is associated with incorrect water consumption calculation procedures and incorrect estimations of meter readings. Consequently, unless these procedures are changed, the magnitude of this term will remain approximately constant over time and be independent of the frequency of the intervention activities. However, only when consumption calculation procedures are extremely imprecise does the magnitude of this component compared to the previous ones prove significant. 
2.1.1. IIAAL $\mathrm{MES}_{\mathrm{ME}}$ - Intervention Independent Annual Apparent Losses Due to Unavoidable Measuring Errors

There is always a technically minimal volume of unmeasured water, defined as the Unavoidable Annual Unmeasured Volume (UAUV), that cannot be completely removed, even in well-maintained and properly managed systems. The reason is simple: water meters have an intrinsic error even at the time of installation (Table 1) [23]. This initial and minimum achievable error mainly depends on the working principle of the meter. Therefore, the $U A U V$ of a water utility can be calculated as a weighted average of the initial errors of the customers' meters installed in the field (Equation (1)). For this weighing procedure, the most accurate parameter that can be used is the customers' annual water consumption.

$$
U A U V=(-1) \times \sum_{i}\left(\varepsilon_{i}(0) \times A C V_{i}\right)
$$

where sub-index $i$ refers to each specific meter type in the utility, $\varepsilon_{i}(0)$ is the average initial weighted error [24] of a meter type $i$, and $A C V_{i}\left(\mathrm{~m}^{3} /\right.$ year) is the Annual Consumption Volume of all the customers using this meter type. As a convention, the weighted error of a meter type $i, \varepsilon_{i}(t), t$ years after installation, has a negative value when the meter is under-registering water consumption from a user, and a positive value if it is over-registering [31]. Consequently, the negative symbol in front of the equation compensates the negative sign of the error to obtain positive figures of apparent losses when meters are under-registering water consumption.

Table 1. The typical ranges for the initial weighted error of different water meter types [32].

\begin{tabular}{ccc}
\hline & Worst Case (\%) & Best Case (\%) \\
\hline Single jet & -5 & -2 \\
Oscillating piston & -1 & +0 \\
AWWA Single-jet & -7 & -3 \\
AWWA Multi-jet & -7 & -3 \\
Fluidic & -7 & -5 \\
Multi-jet & -6 & -2 \\
AWWA Nutating disc & -3 & -1 \\
\hline
\end{tabular}

The actual $A C V_{i}$ of a meter type is, in some cases, difficult to obtain as its calculation requires knowledge of the error of the water meters installed in the system. For this reason, and considering that the $A C V_{i}$ is, at this stage, employed as a weighting parameter, the use of Annual Registered Volume $\left(A R V_{i}\right.$, in $\mathrm{m}^{3}$ /year) may be considered instead. The relationship between $A C V_{i}$ and $A R V_{i}$ is defined in Equation (2).

$$
A C V_{i}=\frac{A R V_{i}}{1-\varepsilon_{i}(t)}
$$

Additionally, it should be highlighted that the lowest possible values of measuring errors associated with water meters do not only depend on the technical characteristics of the meters. There are external influences that also affect those minimum achievable measuring errors. Examples of these factors include the presence of private storage tanks at customers' households, poor water quality, service interruptions, average service pressure, and piping or water appliances technical characteristics. To consider that, an Infrastructure Condition Factor (ICF) can be defined in a similar way to real losses [32]. Generally, this factor adopts a value greater than one and corrects the theoretical minimum value of $U A U V$. A more accurate approximation of ICF can be derived for a particular system conducting a detailed research of the initial measurement errors of the meters as described in Reference [25].

One additional consideration needs to be made when calculating the unavoidable measuring errors. Water meters are complex measuring instruments that incorporate high precision mechanical and/or electronic components. Although water meter manufacturers put a great effort in designing 
reliable and durable devices, they are not completely free of manufacturing defects. Moreover, during the transportation and installation activities, there is a possibility that uncontrolled factors affect the metrology of the meters. This could be the case if a meter is dropped on the ground or solid particles enter the measuring chamber and block the rotating piston or the impeller.

Moreover, and due to their technical complexity, there is a small probability that a critical component of an in-service meter fails without any apparent cause [33]. Obviously, the causes of failures in water meters are diverse and vary depending on several factors like age, totalized volume, working principle and design of the meter, the occurrence of pressure transients, maximum consumption flow rates, water quality, etc. The determination of the parameters that define failure probabilities is a complex field in itself and requires specific studies to establish statistically valid figures for each meter type. To calculate this, a usual assumption is to consider that the volume used by a customer with a non-working meter is not registered at all. Consequently, an estimation of the volume lost associated with meter failures, the Annual Detected Meter Failures Apparent Losses ( $A D M F A L$, in $\mathrm{m}^{3}$ /year), can be obtained based on the average consumption of customers belonging to group $i$, the failure rate probabilities of the installed meters, and the average time between failure and repair/replacement of the meter, as defined by Equation (3):

$$
A D M F A L=\sum_{i}\left(A M F F_{i} / 100 \times A C V_{i} \times A R T_{i}\right)
$$

where $A M F F_{i}\left(\% /\right.$ year) is the Annual Meter Failure Frequency of meter type $i$ and $A R T_{i}$ (years) is the Average Repair Time between the occurrence and the resolution of the meter failure.

Consequently, the overall IIAAL $L_{M E S}$ can be estimated through

$$
I I A A L_{M E S}=I C F \times U A U V+A D M F A L
$$

\subsubsection{IIAAL $\mathrm{ILL}_{\mathrm{IL}}$-Intervention Independent Annual Apparent Losses Due to Illegal Uses of Water}

Unmetered illegal uses of water are a common problem for many water utilities. The importance of this component is related to factors like the water tariff, quality of service, private plumbing system and housing design, per capita income, availability of water, pluviometry, water distribution infrastructure conditions, etc. [34]. In any case, independently of the human and technical resources used by the water utility to confront illegal uses, there will always be an achievable minimum volume below which stolen water cannot be further reduced.

Therefore, illegal uses can be split in two categories: (i) one corresponding to the minimum achievable level of unauthorized uses of water, which is not a function of the number of inspections conducted by the water utility and, (ii) another that can be minimized by increasing the frequency of inspections of customer connections. The first component is, in fact, the Intervention Independent Annual Apparent Losses due to illegal consumption (IIAAL $I L L$, in $\mathrm{m}^{3}$ /year), whereas the second one will be considered below as an intervention dependent component.

It is expected that $I I A A L_{I L L}$ figures are low in developed countries and can reach a significant level in developing or underdeveloped countries. In any case, the IIAALILL can be calculated as follows:

$$
I I A A L_{I L L}=\sum_{j}\left(A I F_{j} / 100 \times A C V_{j}\right)
$$

where sub-index $j$ is related to each customer type in the utility, $A I F_{j}(\% /$ year $)$ is the Average Illegal use Frequency of customers belonging to type $j$ and $A C V_{j}\left(\mathrm{~m}^{3} /\right.$ year) is the Annual Consumption Volume of all the customers belonging to group $j$. 
2.1.3. IIAAL $L_{\mathrm{DH}}$-Intervention Independent Annual Apparent Losses Due to Systematic Data Handling Errors

The third component of IIAAL is related to the manipulation of the water meter readings [34-37]. Currently, there are very few water utilities in the world that have a full implementation of an Advanced Meter Infrastructure (AMI). In most cases, the installation of smart meters and communication infrastructure is only limited to trials with a reduced number of meters. Therefore, the most frequent situation is that water meters are still read manually by field staff and abnormal readings are corrected by automatic algorithms or specialized technicians at the commercial department. The magnitude of data handling errors depends on the particular reading procedures, working practices, and algorithms used by each water company. In the methodology presented, this component is defined as Intervention Independent Annual Apparent Losses due to data handling (IIAAL $L_{D H}$, in $\mathrm{m}^{3}$ /year). Quite frequently, the magnitude of IIAAL $L_{D H}$ is similar every year and independent of the type or age of the meters installed [10]. IIAAL $L_{D H}$ will only change if the current calculations and working procedures used by the utility are changed. As a general rule, the more advanced and automated the water meter reading practices, the lower the importance of this component. Unfortunately, the actual magnitude of this term can only be obtained if a comprehensive audit of the commercial system is conducted. The $I I A A L_{D H}$ is calculated as shown by Equation (6):

$$
I I A A L_{D H}=D H E \times \sum_{i} N M_{i}
$$

where DHE is the Data Handling Error parameter $\left(\mathrm{m}^{3} /\right.$ (meter $\times$ year) and it's assumed to be the same for the whole utility) and $N M_{i}$ is the total number of meters belonging to type $i$ (thus, $\sum_{i} N M_{i}$ is the actual number of meters in the utility).

\subsection{IDAAL-Intervention Dependent Annual Apparent Losses}

The second category of apparent losses, the one that is actually affected by the control and reduction policies implemented by the water utility, is called Intervention Dependent Annual Apparent Losses (IDAAL, in $\mathrm{m}^{3}$ /year). Similar to the concepts applied to find the economic level of real losses, more frequent interventions by the utility reduce the magnitude of this component while delayed interventions will lead to higher losses. In the case of apparent losses, the reason for this can be easily found in the growing nature of the losses; water meters as mechanical devices subject to wear tend to underperform with time. Consequently, according to this principle, the under-registration of water consumption by the water meter increases with time or with totalized volume. A similar concept can also be applied to solid state (non-mechanical) water meters with electronic components. However, in this case, the reason for an increased under-registration of water consumption is related to the increasing frequency of failure of electronic components and battery power with age.

The IDAAL can also be split into two components:

- Intervention Dependent Apparent Losses associated with measuring errors (IDAALMES). This component accounts for the amount of water not registered by a functional water meter. The rate of increase of the volumes not registered by the meters every year depends on the manufacturing and design quality of the meters and the working conditions in the field.

- Intervention Dependent Apparent Losses associated with illegal consumption (IDAAL ILL). Unauthorized uses of water in the system caused by meter tampering and illegal connections are included within this category. The magnitude of the volume stolen every year from the water company is directly related to the inspection frequency of the connections [38]. 
2.2.1. IDAAL $L_{M E S}$-Intervention Dependent Annual Apparent Losses Associated with Measuring Errors

Water meter ageing caused by the wear of mechanical parts frequently leads to more negative measuring errors and higher starting flow rates $[23,39]$, which makes it difficult to register leaks occurring inside the households. After $t$ years from the time of installation, a degraded error curve combined with the consumption pattern of the user yields a weighted error larger than the initial weighted error of the meter. In this respect, most works conducted to date in relation to water meter degradation assume that the weighted error evolves linearly with time (Figure 4) or with the totalized volume $[9,24,40]$. Thus, the weighted error evolution can be expressed as follows:

$$
\varepsilon_{i}(t)=\varepsilon_{i}(0)-A D R_{i} \times t
$$

where $\varepsilon_{i}(0)$ is the initial weighted error of type $i$ meters, $\varepsilon_{i}(t)$ is the average weighted error of type $i$ meters $t$ years after installation and, finally, $A D R_{i}(\% /$ year) represents the Annual Degradation Rate of the weighted error of meters of type $i$.

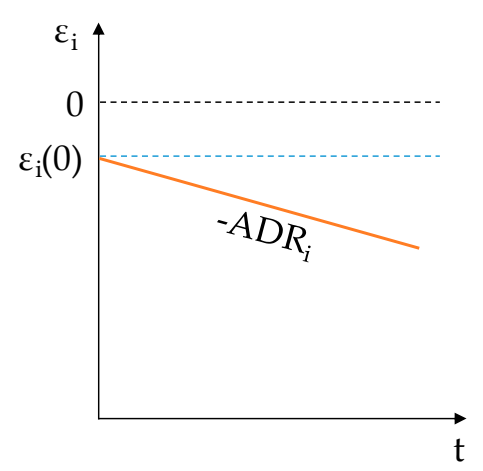

Figure 4. The components and time evolution of apparent losses associated with measuring errors.

Thus, as a water meter degrades with time, the volume of unregistered water will increase. The rate at which apparent losses grow for each meter type is called the Natural Rate of Rise of Apparent Losses due to meter inaccuracies (NRRAL $L_{M E S_{i}}$, in $\mathrm{m}^{3} /$ year $\left.^{2}\right)$. This parameter can be obtained by multiplying the degradation rate of the weighted error of each meter type, $A D R_{i}(\% /$ year), by the total annual consumption volume of the meters belonging to this group, $A C V_{i}\left(\mathrm{~m}^{3} /\right.$ year).

$$
N R R A L_{M E S_{i}}=A D R_{i} / 100 \times A C V_{i}
$$

Consequently, the magnitude of the Intervention Dependent Annual Apparent Losses due to meter inaccuracies for meter type $i$ in year $t, I D A A L_{M E S_{i}}(t)$ (in $\mathrm{m}^{3} /$ year), will be directly related to the average age of the meters of this type $(t)$ and the annual rate of growth of the unmeasured volumes, as defined in Equation (9).

$$
I D A A L_{M E S_{i}}(t)=A D R_{i} / 100 \times A C V_{i} \times t=N R R A L_{M E S_{i}} \times t
$$

The total IDAAL $L_{M E S}(t)$ for the whole system would then be obtained by simply adding all the values calculated for each meter type $i$.

Those utilities without the required data by meter type can conduct an initial rough estimation of the IDAAL $L_{M E S}(t)$ by making the following assumptions:

- $\quad$ Employ a single value of the NRRAL $L_{M E S}^{*}$ for all meters in the system regardless of their type.

- $\quad$ Use an average meter age for all meters in the system, $t^{*}$.

$$
I D A A L_{M E S}^{*}\left(t^{*}\right)=N R R A L_{M E S}^{*} \times t^{*}
$$


2.2.2. IDAAL $L_{I L L}$-Intervention Dependent Annual Apparent Losses Associated with Illegal Connections

Every water utility has a minimum achievable level of illegal consumption $\left(I I A A L_{I L L}\right)$ below of which it is not feasible to obtain further reductions, even if strict control measures and meticulous field inspections are undertaken. This unavoidable level of illegal use strongly depends on the local socio-economic and cultural characteristics.

On top of that minimum level, illegal uses of water may also increase with time if control measures are not implemented [37]. In this case, the approach followed is similar to the one previously described for the measuring errors. For each type of customer $j$ there will be an Annual Illegal Consumption Increasing Rate $\left(A I C R_{j}\right.$, in \%/year). This rate represents the percentage of users per year that may become illegal given the control measures currently adopted by the utility. To consider an average single index for the appearance of illegal uses across the system, a weighted average of AICR can be calculated. The overall rate at which the illegal uses increase within the water system is defined by the Natural Rate of Rise of Apparent Losses due to illegal connections (NRRAL $I L L$, in $\mathrm{m}^{3} /$ year $\left.^{2}\right)$ :

$$
N R R A L_{I L L_{j}}=A I C R_{j} / 100 \times A C V_{j}
$$

Subsequently, the magnitude of the Intervention Dependent Annual Apparent Losses due to illegal consumption for customer type $j$, after $t$ years from the last inspection, $I D A A L_{I L L_{j}}(t)$ (in $\mathrm{m}^{3}$ /year), will be obtained as

$$
N R R A L_{I L L_{j}}(t)=A I C R_{j} / 100 \times A C V_{j} \times t=N R R A L_{I L L_{j}} \times t
$$

The total IDAAL $I L L_{j}(t)$ for the whole system would then be obtained by simply adding all the values calculated for each customer type $j$. Additionally, for systems with no data available, it is possible to make a rough estimation of this parameter $I D A A L_{I L L}^{*}(t)$ by simply using a single figure for all the customers in the system.

\section{Policies to Reduce Apparent Losses and Related Costs}

Apparent losses reduction policies refer, in the present work, to the activities conducted periodically that help to reduce the total amount of water served to the customers and not accounted for by the utility (either because it is stolen or not measured by the installed meters). The various intervention activities implemented by the utility will only affect the intervention dependent components of the losses, i.e., the IDAAL. In other words, the intensity of the activities and actions aimed at reducing water losses will not affect the volumes associated with IIAAL as these volumes are related to the structural parameters of the water system and can only be improved if these structural characteristics are modified. For example, the $I D A A L_{M E S}$ could be minimised if the water utility replaces velocity domestic meters with solid-state meters [24].

The two most obvious intervention activities carried out by water utilities are meter replacements to improve measuring errors and field inspections of customers' connections to reduce the number of illegal users and meter tampering. The intensity at which each one of these activities is implemented is defined by the time elapsed between two interventions. In the case of IDAAL period refers to the time frame that it takes a water company to replace a meter $\left(T_{M E S}\right)$ since it was installed, while in the case of $I D A A L_{I L L}$, the intervention period is related to the time required to inspect all water connections $\left(T_{I L L}\right)$. These intervention periods, which take into account the complete system, are named $T_{M E S}$ and $T_{I L L}$, respectively, and expressed in years. A sub-index $i$ or $j$ is added when these parameters refer to a specific meter or customer types respectively. The longer the periods, the less intensive the water loss reduction activities and the lower the annual cost of such activities, as fewer resources are needed to carry them out. The magnitude of $T_{M E S}$ and $T_{I L L}$, as defined by 
the water utility, characterise the average annual value (Equations (13) and (14)) associated with that intervention policy and the variation range of each one of the components of the IDAAL (Figure 5).

$$
\begin{aligned}
\overline{I D A A L_{M E S_{i}}} & =\frac{1}{2} N R A A L_{M E S_{i}} \times T_{M E S_{i}} \\
\overline{I D A A L_{I L L_{j}}} & =\frac{1}{2} N R A A L_{I L L_{j}} \times T_{I L L_{j}}
\end{aligned}
$$
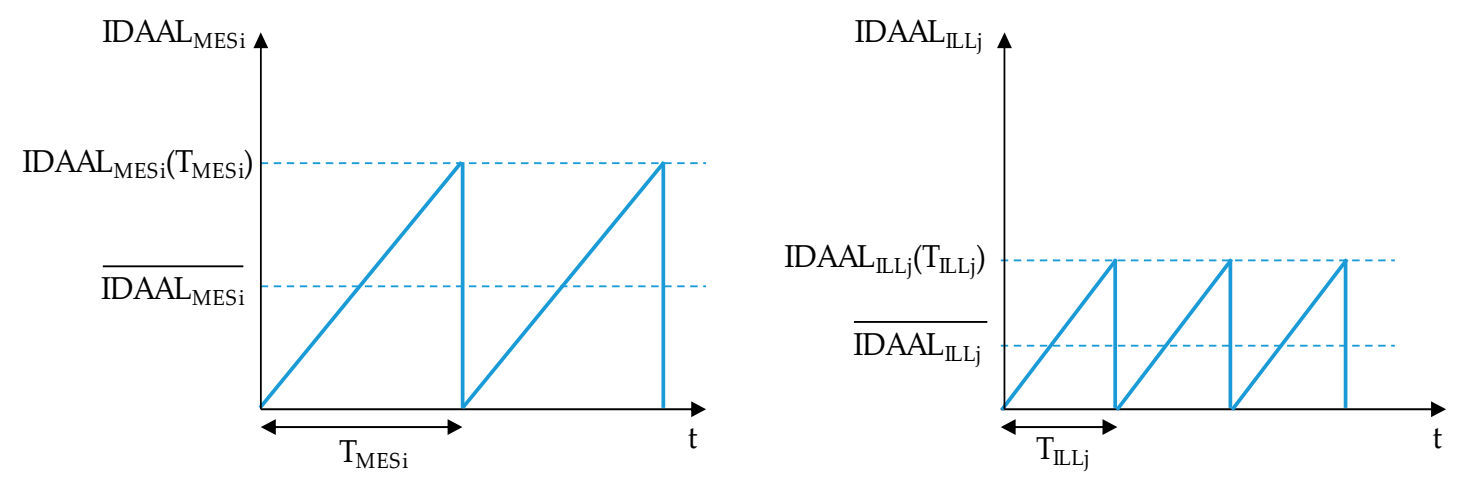

Figure 5. The time evolution of $I D A A L_{M E S i}$ and IDAAL ILLj and average values associated with $T_{M E S i}$ and $T_{I L L j}$.

Apparent loss control policies are not solely defined by the magnitude of the losses. A detailed analysis of the costs required to implement these periodic activities also needs to be conducted. Similarly to the approach followed for real losses [41], the parameters $T I C_{M E S_{i}}$ and $T I C_{I L L_{j}}$ (both in $€$ ) define the total intervention costs, i.e., the cost of renewing the meters' stock belonging to type $i$ and the cost of inspecting all customers' connections of type $j$. If these costs are expressed on an annual basis, they can be calculated as

$$
\begin{gathered}
A I B_{M E S_{i}}=\frac{T I C_{M E S_{i}}}{T_{M E S_{i}}}=\frac{T I C_{M E S_{i}} \times N R R A L_{M E S_{i}}}{2}\left(\frac{1}{\overline{I D A A L_{M E S_{i}}}}\right) \\
A I B_{I L L_{j}}=\frac{T I C_{I L L_{j}}}{T_{I L L_{j}}}=\frac{T I C_{I L L_{j}} \times N R R A L_{I L L_{j}}}{2}\left(\frac{1}{\overline{I D A A L_{I L L_{j}}}}\right)
\end{gathered}
$$

where $A I B_{M E S_{i}}(€ /$ year) represents the average Annual Intervention Budget of replacing the type $i$ meters, and $A I B_{I L L_{j}}(€ /$ year) represents the Annual Inspection Budget of customers' connections of type $j$.

This way, each policy is now fully characterized by means of two parameters: annual water losses

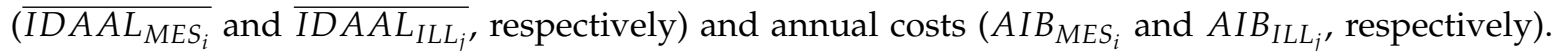
A third parameter, the period between interventions ( $T_{M E S}$ and $T_{I L L}$, respectively) relates losses (Equations (13) and (14)) and costs (Equations (15) and (16)). In other words, depending on the duration of these periods, the parameters that characterise each specific policy are automatically determined.

The relationship between these three parameters can be illustrated by representing water losses (IDAAL, horizontal axis) against the intervention costs ( $A I B$, vertical axis), as depicted in Figure 6. In this figure, two particular water reduction policies, 1 and 2, define two different intervention intensities. Scenario 1 would correspond a situation in which the annual budget for reducing water losses is low and, consequently, the annual volume of apparent losses are considerable. On the other hand, in scenario 2 , the water utility has increased the intervention frequency, increasing the budget, and has managed to reduce the apparent loss volumes. 


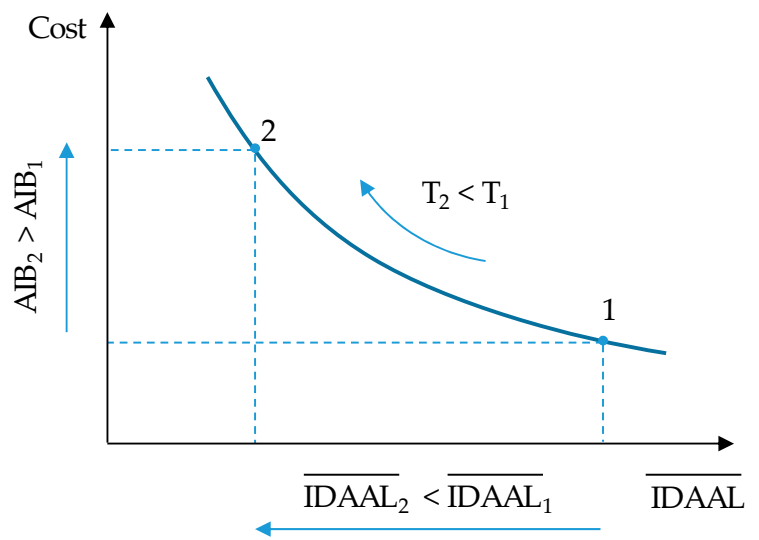

Figure 6. The general main cost curve for one intervention policy.

\section{Calculation of Economic Level of Apparent Losses}

The Economic Level of Apparent Losses (ELAL, in $\mathrm{m}^{3}$ /year) is defined as the magnitude of apparent losses for which the total costs, calculated as the sum of the control and reduction policies and the utility's cost of the water losses, reach a minimum.

The ELAL calculation can be conducted using a basic econometric analysis. Both control policies, the one that manages the ageing of the meters and the one supervising illegal uses, are independent in terms of costs, volumes, and influencing parameters. Therefore, the analysis should be carried out separately for each one of them using the same methodology, which is equivalent to the one currently used and widely accepted for real losses [32,40-42].

However, one more element is needed to perform that analysis- the cost of the water loss volumes. Conversely, to what is considered in real losses, the utility cost of one cubic meter of apparent losses is not the cost of producing it, but the amount a customer would have paid for it if it had been measured by the water meter [24,33]. This applies to both apparent losses caused by meter inaccuracies and illegal uses. Considering this, the cost associated with the current apparent water losses can be calculated as

$$
\begin{aligned}
A C W_{M E S_{i}} & =P W \times \overline{I D A A L_{M E S_{i}}} \\
A C W_{I L L_{j}} & =P W \times \overline{I D A A L_{I L L_{j}}}
\end{aligned}
$$

where $A C W_{M E S_{i}}\left(€ /\right.$ years) is the Annual Cost of Water lost due to measuring errors, $A C W_{I L L_{j}}(€ /$ years) is the Annual Cost of Water lost due to illegal uses and $P W\left(€ / \mathrm{m}^{3}\right)$ is the selling Price of Water. At this point, it should be noted that the exact calculation of this price may become very complex when block tariffs are applied. For a precise calculation, the $A C W_{M E S_{i}}$ and $A C W_{I L L_{j}}$ should always consider the selling price of the last cubic meter sold to each customer.

The Total Annual Costs of each control policy (TAC $M E S_{i}$ or $T A C_{I L L_{j}}$, both in $€ /$ year) for a given amount of losses $\left(\overline{I D A A L_{M E S_{i}}}\right.$ or $\overline{I D A A L_{I L L_{j}}}$ ) can then be calculated as the sum of the annual intervention budgets $\left(A I B_{M E S}\right.$ or $\left.A I B_{I L L}\right)$ and the annual cost of water $\left(A C W_{M E S_{i}}\right.$ or $\left.A C W_{I L L_{j}}\right)$ :

$$
\begin{gathered}
T A C_{M E S_{i}}=A I B_{M E S_{i}}+A C W_{M E S_{i}}=\frac{T I C_{M S_{i}} \times N R R A L_{M E S_{i}}}{2}\left(\frac{1}{\overline{I D A A L_{M E S_{i}}}}\right)+P W \times \overline{I D A A L_{M E S_{i}}} \\
T A C_{I L L_{j}}=A I B_{I L L_{j}}+A C W_{I L L_{j}}=\frac{T I C_{I L L_{j}} \times N R R A L_{I L L_{j}}}{2}\left(\frac{1}{\overline{I D A A L_{I L L_{j}}}}\right)+P W \times \overline{I D A A L_{I L L_{j}}}
\end{gathered}
$$

While the term associated with intervention budgets $(A I B)$ is higher with lower values of losses $(\overline{I D A A L})$, the term corresponding to the cost of water $(A C W)$ shows the opposite behaviour. The graphical representation of these relations (Figure 7) demonstrates that the Total cost function (TAC) reaches a minimum value for which the total costs are minimised. 


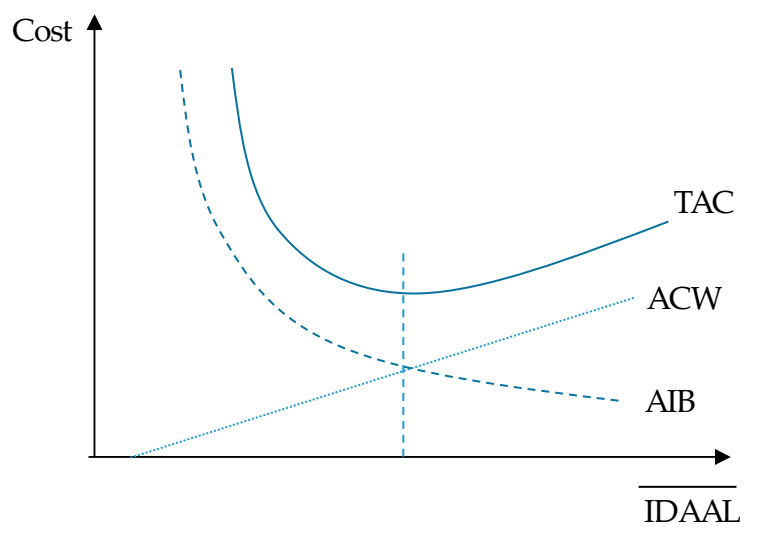

Figure 7. The complete three costs curves for one intervention policy.

Mathematically, the minimum of the cost function can be found by equalizing its derivatives to zero $\left(\frac{d\left(T A C_{M E S}\right)}{d\left(I D A A L_{M E S}\right)}=0\right.$ and $\left.\frac{d\left(T A C_{I L L}\right)}{d\left(I D A A L_{I L L}\right)}=0\right)$. By doing so, it is possible to obtain an analytical expression providing the optimal value for measuring errors and illegal uses of water.

$$
\begin{aligned}
\overline{I D A A L_{M E S_{i}}^{O P T}} & =\sqrt{\frac{T I C_{M E S_{i}} \times N R R A L_{M E S_{i}}}{2 \times P W}} \\
\overline{I D A A L_{I L L_{j}}^{O P T}} & =\sqrt{\frac{T I C_{I L L_{j}} \times N R R A L_{I L L_{j}}}{2 \times P W}}
\end{aligned}
$$

where $I D A A L_{M E S_{i}}^{O P T}$ and IDAAL $L_{I L L_{j}}^{O P T}\left(\mathrm{~m}^{3} /\right.$ year $)$ are, respectively, the optimum levels of each intervention dependent component of apparent losses.

After finding the level of losses that leads to the minimum of the cost function of each policy, the overall amount of apparent losses will be the sum of the current intervention independent losses and the economic level of the intervention dependent components, as shown in Equation (23).

$$
\begin{aligned}
E L A L=I I A A L & +\overline{I D A A L^{O P T}} \\
& =\left(I I A A L_{M E S}+I I A A L_{I L L}+I I A A L_{D H}\right)+\left(\sum_{i} \overline{I D A A L_{M E S_{i}}^{O P T}}\right. \\
& \left.+\sum_{j} \overline{I D A A L_{I L L_{j}}^{O P T}}\right)
\end{aligned}
$$

From the above, the remaining parameters related to an optimized policy can be calculated as follows:

- Intervention costs (from Equation (15) for $A I B_{M E S_{i}}^{O P T}$ and Equation (16) for $A I B_{I L L_{j}}^{O P T}$ ):

$$
\begin{aligned}
A I B_{M E S_{i}}^{O P T} & =\frac{1}{2} \frac{T I C_{M E S_{i}} \times N R R A L_{M E S_{i}}}{\overline{I D A A L_{M E S_{i}}^{O P T}}} \\
A I B_{I L L_{j}}^{O P T} & =\frac{1}{2} \frac{T I C_{I L L_{j}} \times N R R A L_{I L L_{j}}}{\overline{I D A A L_{I L L_{j}}^{O P T}}} \\
A I B^{O P T} & =\sum_{i} A I B_{M E S_{i}}^{O P T}+\sum_{j} A I B_{I L L_{j}}^{O P T}
\end{aligned}
$$

- Optimum intervention periods (from Equations (15), (21), and (24) for $T_{M E S_{i}}^{O P T}$, and Equations (16), (22), and (25) for $T_{I L L_{j}}^{O P T}$ ): 


$$
\begin{gathered}
T_{M E S_{i}}^{O P T}=\frac{T I C_{M E S_{i}}}{A I B_{M E S_{i}}^{O P T_{i}}}=\sqrt{\frac{2 \times T I C_{M E S_{i}}}{N R R A L_{M E S_{i}} \times P W}} \\
T_{I L L_{j}}^{O P T}=\sqrt{\frac{2 \times T I C_{I L L_{j}}}{N R R A L_{I L L_{j}} \times P W}}
\end{gathered}
$$

- Percentage of water meters or customers' connections annually replaced or inspected, respectively, by each policy:

$$
\begin{aligned}
P_{A I M_{M E S_{i}}^{O P T}}^{O P E} & =\frac{1}{T_{M E S_{i}}^{O P T}} \times 100 \\
\text { PAIM }_{I L L_{j}}^{O P T} & =\frac{1}{T_{I L L_{j}}^{O P T}} \times 100
\end{aligned}
$$

The minimum of the cost function related to apparent losses is achieved by applying the optimal intervention period for the meter replacement and inspection of customers' connections. These intervention periods should be calculated independently to each other. As presented in the second case study (Appendix B), the costs can be significantly reduced if meters are optimally replaced and the inspections are conducted with an adequate periodicity. More precisely, for the case study presented, the total costs of apparent loss management can be reduced by $11 \%$ by modifying the intervention periods. The proposed meter replacement periods are $30 \%$ shorter for three meter types and $20 \%$ larger for the remaining meter type. The optimal inspection interval of the customers' connections is $100 \%$ longer.

\section{Apparent Loss Indicators}

In order to benchmark the apparent loss management performance of a water utility the following indicators are proposed based on the classification used in this work:

- Apparent Losses Index $(A L I)$. This indicator is a measure of how the current apparent losses compare to the minimum achievable value. This indicator should always be greater than one.

$$
A L I=\frac{C A A L}{I I A A L}
$$

- Apparent Losses Economic Index (ALEI). This indicator measures how close the utility losses are with respect to the economic level of losses. The target for a properly managed water utility is to attain a value for the $A L E I$ as close to one as possible.

$$
A L E I=\frac{C A A L}{E L A L}
$$

- Apparent Losses Economic Potential Index (ALEPI). The ALEPI is not directly related to the water loss management policies of the utility. It measures how far the economic level is from the unavoidable level of losses.

$$
A L E P I=\frac{E L A L}{I I A A L}
$$

Finally, all three indicators defined above can be related as

$$
A L I=A L E I \times A L E P I
$$




\section{Conclusions}

In addition to the IWA apparent losses components defined in the traditional water balance, this manuscript proposes two categories taking into account their dependency with the regular intervention policies implemented by the water utility to mitigate water losses. The resulting constituents have been comprehensively described and explained in the text and brief indications for their quantification have been provided.

The calculation of the economic level of apparent losses has been proposed based on this new categorization. It assumes that intervention dependent components constantly grow with time if the water utility does not introduce adequate measures to control and reduce losses. On the contrary, intervention independent terms are inherent of the water system and can only be improved if structural measures are introduced. Intervention frequency does not modify the actual value of this type of loss. Therefore, the economic optimization only applies to the intervention dependent terms as they are the only ones that can be affected by the amount of resources a water utility puts on the field to reduce water losses.

The main intervention activities that can be conducted by the water company to reduce apparent losses are water meter replacement and customers' connection inspections. Therefore, the work presented allows for a quick calculation of the optimum replacement period of the meters and the inspection of the customers' connections. Once these figures have been obtained it is possible to derive the economic level of apparent losses and the investment required to achieve the desired level. The proposed procedure follows the same approach and concepts as the well-accepted procedure commonly used to find the economic level of real losses. Additionally, the number of parameters required has been reduced to a minimum and the calculations have been deliberately kept simple to ensure the applicability of the methodology. Additionally, the manuscript presents a set of performance indicators to benchmark the current level of apparent losses with respect to the minimum achievable and the economic level of losses.

With this work, the authors expect to connect the techniques available to calculate the economic level of apparent losses with the ones currently used for real losses. In both cases, the assumptions, parameters, and simplifications made are comparable and the resulting equations have an undeniable similarity.

Author Contributions: Conceptualization F.J.A.; Methodology F.J.A., R.C., J.S. and R.J.-R.; Analysis F.J.A., R.C. and J.S.; Writing, review and editing F.J.A., R.C., J.S. and R.J.-R.

Conflicts of Interest: The authors declare no conflict of interest.

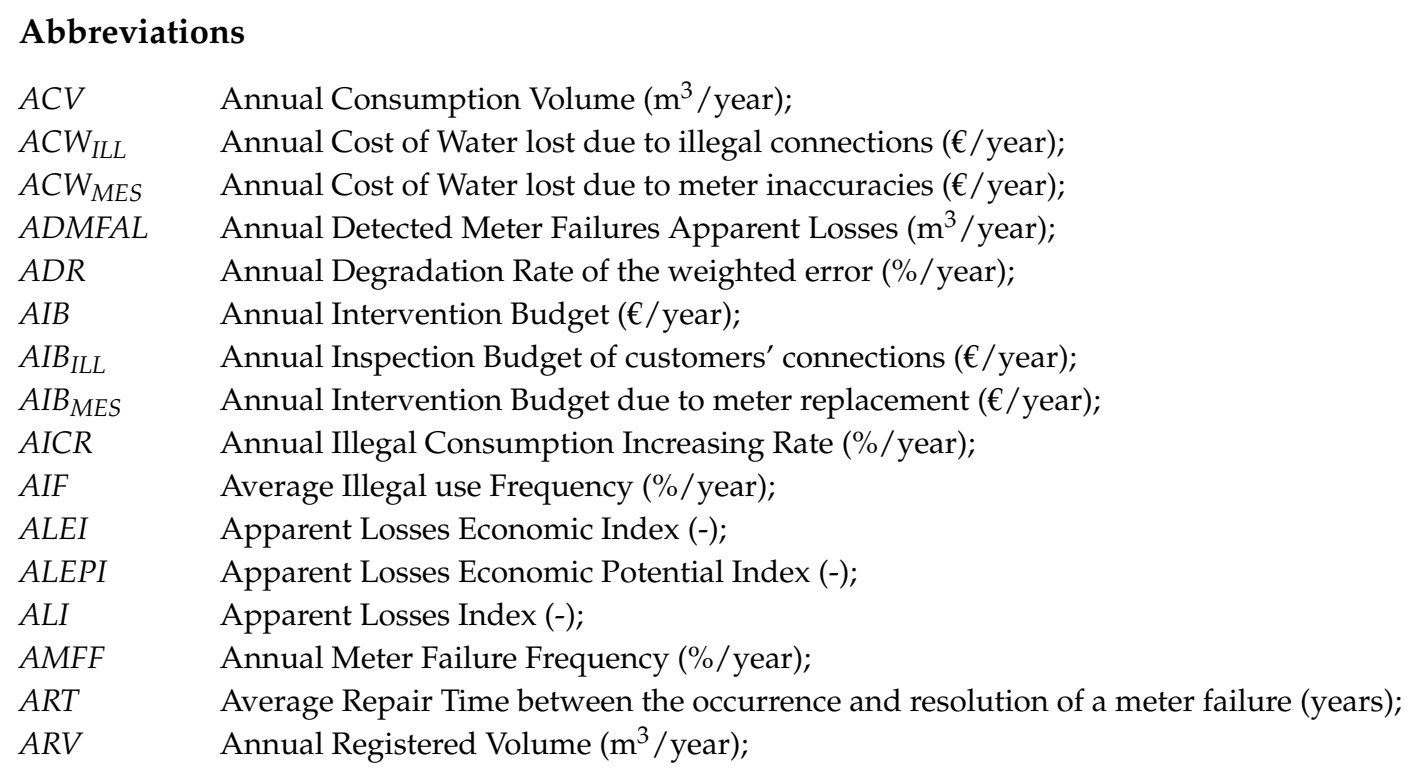


CAAL Current Annual Apparent Losses ( $\mathrm{m}^{3} /$ year);

$D H E \quad$ Data Handling Error parameter $\left(\mathrm{m}^{3} /(\right.$ meter $\times$ year $)$;

ELAL Economic Level of Apparent Losses ( $\mathrm{m}^{3} /$ year);

$\varepsilon(t) \quad$ Average Weighted Error depending on time (\%);

$\varepsilon(0) \quad$ Average Initial Weighted Error (\%);

$i \quad$ Meter type;

ICF Infrastructure Condition Factor (-);

IDAAL Intervention Dependent Annual Apparent Losses ( $\mathrm{m}^{3} /$ year);

$I D A A L_{I L L}$ Intervention Dependent Annual Apparent Losses due to illegal connections ( $\mathrm{m}^{3} /$ year);

$I D A A L_{M E S}$ Intervention Dependent Annual Apparent Losses due to meter inaccuracies ( $\mathrm{m}^{3} /$ year);

IIAAL Intervention Independent Annual Apparent Losses ( $\mathrm{m}^{3} /$ year);

IIAAL $L_{D H}$ Intervention Independent Annual Apparent Losses due to data handling errors ( $\mathrm{m}^{3} /$ year);

IIAAL ILL Intervention Independent Annual Apparent Losses due to illegal connections ( $\mathrm{m}^{3} /$ year);

IIAAL $L_{M E S}$ Intervention Independent Annual Apparent Losses due to meter inaccuracies $\left(\mathrm{m}^{3} /\right.$ year);

j Customer group;

NM Number of Meters installed (meters);

NRRAL ILL Natural Rate of Rise of Apparent Losses due to illegal connections $\left(\mathrm{m}^{3} /\right.$ year $\left.^{2}\right)$;

NRRAL $M E S$ Natural Rate of Rise of Apparent Losses due to meter inaccuracies $\left(\mathrm{m}^{3} / \mathrm{year}^{2}\right)$;

PAIM ILL Percentage of Annually Inspected Meters (\%/year);

PAIM $\quad$ Percentage of Annually Replaced Meters (\%/year);

$P W \quad$ Selling Price of water $\left(€ / \mathrm{m}^{3}\right)$;

$t \quad$ Time Period (years);

$T_{I L L} \quad$ Time required to inspect all water connections (years);

$T_{M E S} \quad$ Time required to replace all water meters (years);

TAC Total Annual Cost $(€ /$ year);

TAC ILL Total Annual Cost of the policy associated with the inspection of customers' connections $(€ /$ year);

TAC $C_{\text {MES }} \quad$ Total Annual Cost of the policy associated with meter replacements $(€ /$ year)

$T_{I C L} \quad$ Total Intervention Cost of inspections $(€)$;

TIC Total Intervention Cost of replacements $(€)$;

UAUV Unavoidable Annual Unmeasured Volume $\left(\mathrm{m}^{3} /\right.$ year $)$;

\section{Appendix A. Case Study 1-Example for a Water Utility with Basic Data}

\section{Appendix A.1. General Data}

To show the applicability of the economic model presented, a simple case study-only one type of meter (velocity) and one type of customer (residential) — is analysed. The data of the fictitious system is provided in Table A1.

Table A1. Case study $1-$ General data meter and consumer types.

\begin{tabular}{|c|c|}
\hline USER TYPE & RESIDENTIAL \\
\hline METER TYPE & VELOCITY \\
\hline NM (meters) & 30,000 \\
\hline$A C V\left(\mathrm{~m}^{3} /\right.$ year $)$ & $4,500,000$ \\
\hline$\varepsilon(0)(\%)$ & -5 \\
\hline AMFF (\%/year) & 0.5 \\
\hline$A R T$ (years) & 0.7 \\
\hline AIF (\%/year) & 0.3 \\
\hline$A D R(\% / y e a r)$ & 0.5 \\
\hline AICR (\%/year) & 0.15 \\
\hline$T_{M E S}$ (years) & 14 \\
\hline$T_{I L L}$ (years) & 3 \\
\hline$U I C_{M E S}(€ /$ meter $)$ & 32 \\
\hline$U I C_{I L L}(€ /$ meter $)$ & 5 \\
\hline ICF & 1.21 \\
\hline$D H E\left(\mathrm{~m}^{3} /(\right.$ meter $\times$ year $\left.)\right)$ & 0.180 \\
\hline$P W\left(€ / \mathrm{m}^{3}\right)$ & 0.9 \\
\hline
\end{tabular}


All the calculations are presented in the same order as the contents and equations that have been developed in the main body of the paper: components of apparent losses, current total apparent losses, costs of current control and reduction policies, calculation of the ELAL, and other apparent losses benchmarks.

Appendix A.2. IIAAL-(Current) Intervention Independent Annual Apparent Losses

The IIAAL is constituted by three different components. The calculation of the first one, due to meter measuring inaccuracies, relies on the value $U A U V$ (Equation (1)):

$$
U A U V=(-1) \times \varepsilon(0) \times A C V=225,000 \frac{\mathrm{m}^{3}}{\text { year }}
$$

and also on the value of $A D M F A L$ (Equation (3)):

$$
A D M F A L=A M F F \times A C V \times A R T=15,750 \frac{\mathrm{m}^{3}}{\text { year }}
$$

Therefore, the first component of IIAAL results in (Equation (4))

$$
I I A A L_{M E S}=I C F \times U A U V+A D M F A L=288,000 \frac{\mathrm{m}^{3}}{\text { year }}
$$

The second component, due to illegal consumption, is calculated through (Equation (5))

$$
I I A A L_{I L L}=A I F \times A C V=13,500 \frac{\mathrm{m}^{3}}{\text { year }}
$$

In third place, the apparent losses caused by data handling errors are (Equation (6))

$$
I I A A L_{D H}=D H E \times N M=5400 \frac{\mathrm{m}^{3}}{\text { year }}
$$

Finally, the value of IIAAL can be calculated as the sum of the three previous components (Figure 3):

$$
I I A A L=I I A A L_{M E S}+I I A A L_{I L L}+I I A A L_{D H}=306,900 \frac{\mathrm{m}^{3}}{\text { year }}
$$

Appendix A.3. IDAAL—(Current) Intervention Dependent Annual Apparent Losses

The IDAAL has two components. The calculation of the first one, due to metering inaccuracies, begins by solving the NRRAL MES (Equation (8)):

$$
N R R A L_{M E S}=A D R / 100 \times A C V=22,500 \frac{\mathrm{m}^{3}}{\text { year }}
$$

and the average value, $\overline{I D A A L_{M E S}}$, is (Equation (13))

$$
\overline{I D A A L_{M E S}}=\frac{1}{2} N R R A L_{M E S} \times T_{M E S}=157,500 \frac{\mathrm{m}^{3}}{\text { year }}
$$

Likewise, the second component, associated with illegal consumption, can be obtained through $N R R A L_{I L L}$ (Equation (11)):

$$
N R R A L_{I L L}=A I C R / 100 \times A C V=6750 \frac{\mathrm{m}^{3}}{\text { year }}
$$


and the average value, $\overline{I D A A L_{I L L}}$, is (Equation (14))

$$
\overline{I D A A L_{I L L}}=\frac{1}{2} N R R A L_{I L L} \times T_{I L L}=10,125 \frac{\mathrm{m}^{3}}{\text { year }}
$$

Consequently, the overall value of $\overline{I D A A L}$ can be calculated as the sum of the two components (Figure 3):

$$
\overline{I D A A L}=\overline{I D A A L_{M E S}}+\overline{I D A A L_{I L L}}=167,625 \frac{\mathrm{m}^{3}}{\text { year }}
$$

Appendix A.4. CAAL—Current Annual Apparent Losses

The total current annual apparent losses, $C A A L$, is obtained by adding the two categories calculated in the previous sections (Figure 3):

$$
C A A L=I I A A L+\overline{I D A A L}=474,525 \frac{\mathrm{m}^{3}}{\text { year }}
$$

Considering the varying nature of the different apparent losses components, it is possible to plot their evolution with time (annual losses vs. time) as shown in Figure A1. The various magnitudes of the parameters used in the calculations, such as the different slopes or intervention periods, can be easily identified for this particular case study.

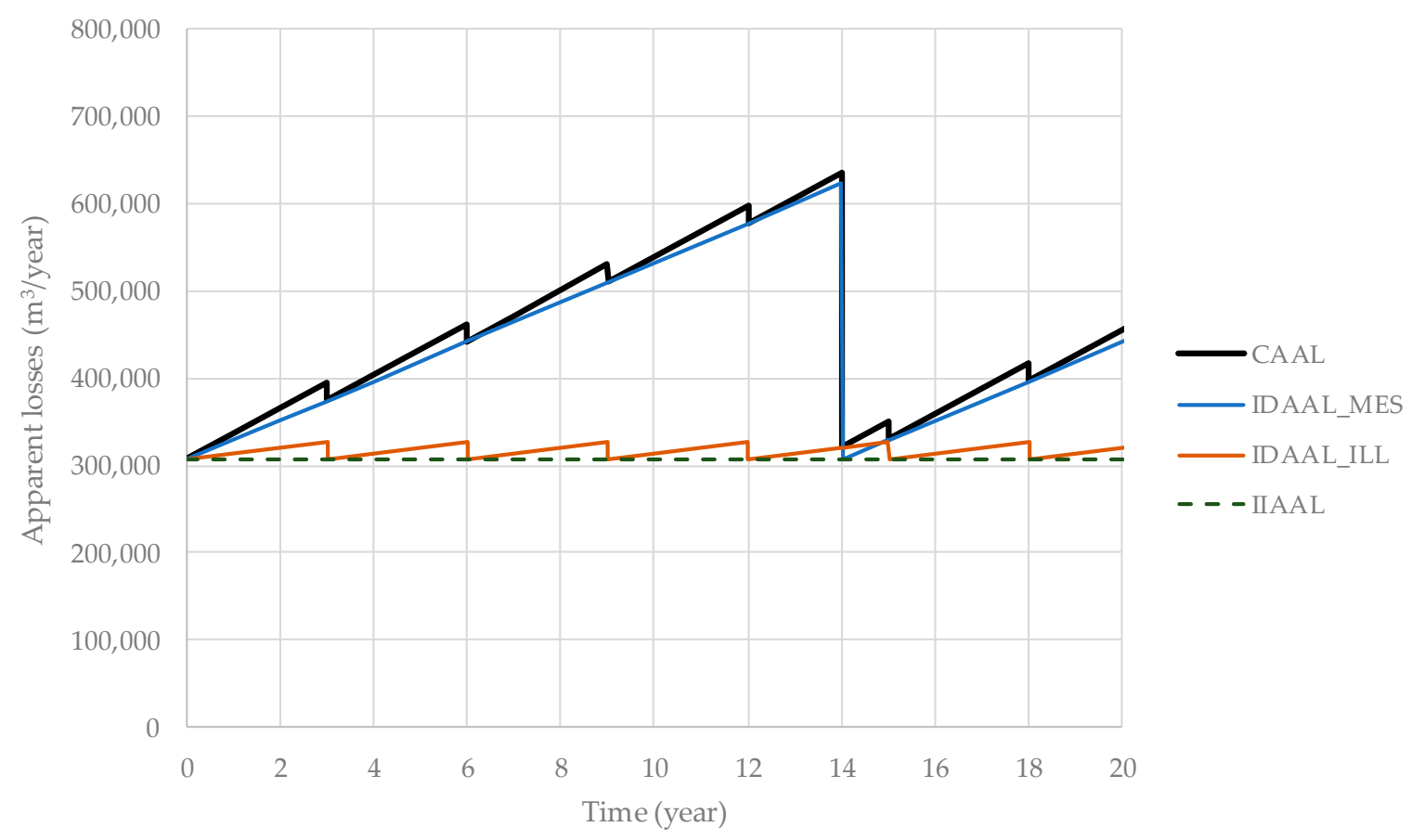

Figure A1. Case study 1 -Time evolution of the various components of apparent losses (IIAAL, $I D A A L_{M E S}$, and IDAAL $\left.L_{I L L}\right)$. 
Appendix A.5. TAC—Total Annual Costs of Current Control Policies

To calculate the total costs of each intervention policy (meter replacement and meter inspection), the first step is to obtain the total intervention costs by taking into account the unitary cost per meter and the total number of meters. For the case of the meter replacement policy, the total intervention costs are

$$
T I C_{M E S}=U I C_{M E S} \times N M=960,000 €
$$

This way, the annual intervention budget is obtained (Equation (15)):

$$
A I B_{M E S}=\frac{T I C_{M E S}}{T_{M E S}}=68,571 \frac{€}{\text { year }}
$$

The annual cost of lost water caused by measuring error is (Equation (17))

$$
A C W_{M E S}=P W \times \overline{I D A A L_{M E S}}=141,750 \frac{€}{\text { year }}
$$

and the total annual costs are (Equation (19))

$$
T A C_{M E S}=A I B_{M E S}+A C W_{M E S}=210,321 \frac{€}{\text { year }}
$$

Similar calculations can then be performed for the customers' connections inspection policy. The total intervention costs are

$$
T I C_{I L L}=U I C_{I L L} \times N M=150,000 €
$$

and the annual intervention budget is obtained (Equation (16)):

$$
A I B_{I L L}=\frac{T I C_{I L L}}{T_{I L L}}=50,000 \frac{€}{\text { year }}
$$

The annual cost of lost water by illegal uses is (Equation (18))

$$
A C W_{I L L}=P W \times \overline{I D A A L_{I L L}}=9113 \frac{€}{\text { year }}
$$

and the total annual costs are (Equation (20))

$$
T A C_{I L L}=A I B_{I L L}+A C W_{I L L}=59,113 \frac{€}{\text { year }}
$$

Figure $\mathrm{A} 2$ shows both costs curves, $A I B_{M E S}$ and $A I B_{I L L}$, for both policies. The particular points that spot the current values for each one are also highlighted in the figure.

Finally, the total costs of both policies are

$$
T A C=T A C_{M E S}+T A C_{I L L}=269,434 \frac{€}{\text { year }}
$$




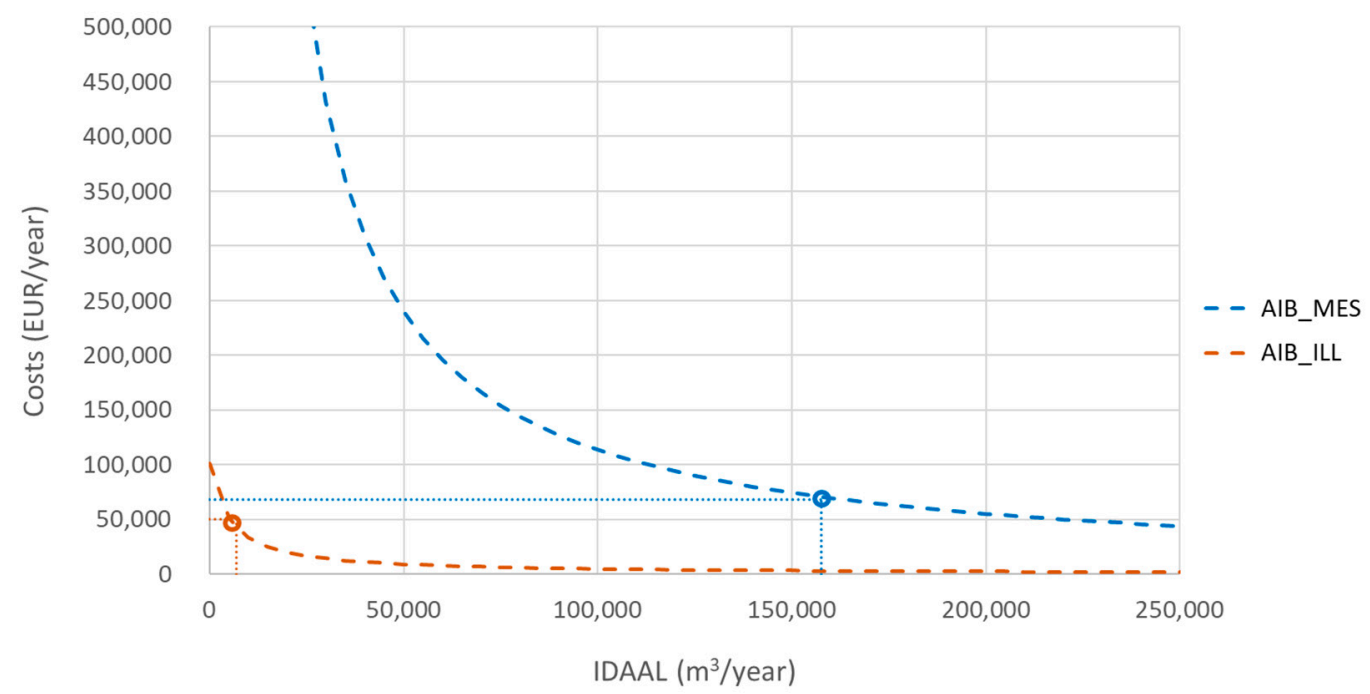

Figure A2. Case study $1-A I B_{M E S}$ and $A I B_{I L L}$ curves.

Appendix A.6. ELAL—Control Policies Frequency and the Economic Level of Apparent Losses

As explained above, the cost of each policy should be minimized independently from each other. The economic level of losses volume associated with the meter replacement policy can be calculated through (Equation (21))

$$
\overline{I D A A L_{M E S}^{O P T}}=\sqrt{\frac{T I C_{M E S} \times N R R A L_{M E S}}{2 \times P W}}=109,545 \frac{\mathrm{m}^{3}}{\text { year }}
$$

The resulting economic replacement period is (Equation (27))

$$
T_{M E S}^{O P T}=\sqrt{\frac{2 \times T I C_{M E S}}{N R R A L_{M E S} \times P W}}=9.74 \text { years }
$$

The percentage of the total stock of meters that is replaced every year is (Equation (29))

$$
P A I M_{M E S}^{O P T}=\frac{1}{T_{M E S}^{O P T}} \times 100=10.3 \%
$$

The cost of the economic annual intervention budget equals the value of the lost water (Equations (15) and (17)):

$$
A I B_{M E S}^{O P T}=\frac{T I C_{M E S}}{T_{M E S}^{O P T}}=A C W_{M E S}^{O P T}=P W \times \overline{I D A A L_{M E S}^{O P T}}=98,590 \frac{€}{\text { year }}
$$

and the resulting minimized total annual costs are (Equation (19))

$$
T A C_{M E S}^{O P T}=A I B_{M E S}^{O P T}+A C W_{M E S}^{O P T}=197,180 \frac{€}{\text { year }}
$$

The parallel calculations for the meter inspection policy, focused on illegal consumptions, are (Equations (16), (18), (22), (28), and (30)):

$$
\overline{I D A A L_{I L L}^{O P T}}=\sqrt{\frac{T I C_{I L L} \times N R R A L_{I L L}}{2 \times P W}}=23,717 \frac{\mathrm{m}^{3}}{\text { year }}
$$




$$
\begin{gathered}
T_{I L L}^{O P T}=\sqrt{\frac{2 \times T I C_{I L L}}{N R R A L_{I L L} \times P W}}=7.03 \text { years } \\
P A I M_{I L L}^{O P T}=\frac{1}{T_{I L L}^{O P T}} \times 100=14.2 \% \\
A I B_{I L L}^{O P T}=\frac{T I C_{I L L}}{T_{I L L}^{O P T}}=A C W_{I L L}^{O P T}=P W \times \overline{I D A A L_{I L L}^{O P T}}=21,345 \frac{€}{\text { year }}
\end{gathered}
$$

and the total minimized annual costs are (Equation (20))

$$
T A C_{I L L}^{O P T}=A I B_{I L L}^{O P T}+A C W_{I L L}^{O P T}=42,691 \frac{€}{\text { year }}
$$

Figures A3 and A4 show, respectively, the three costs curves for the meter replacement policy and the result of the minimization of the costs function.

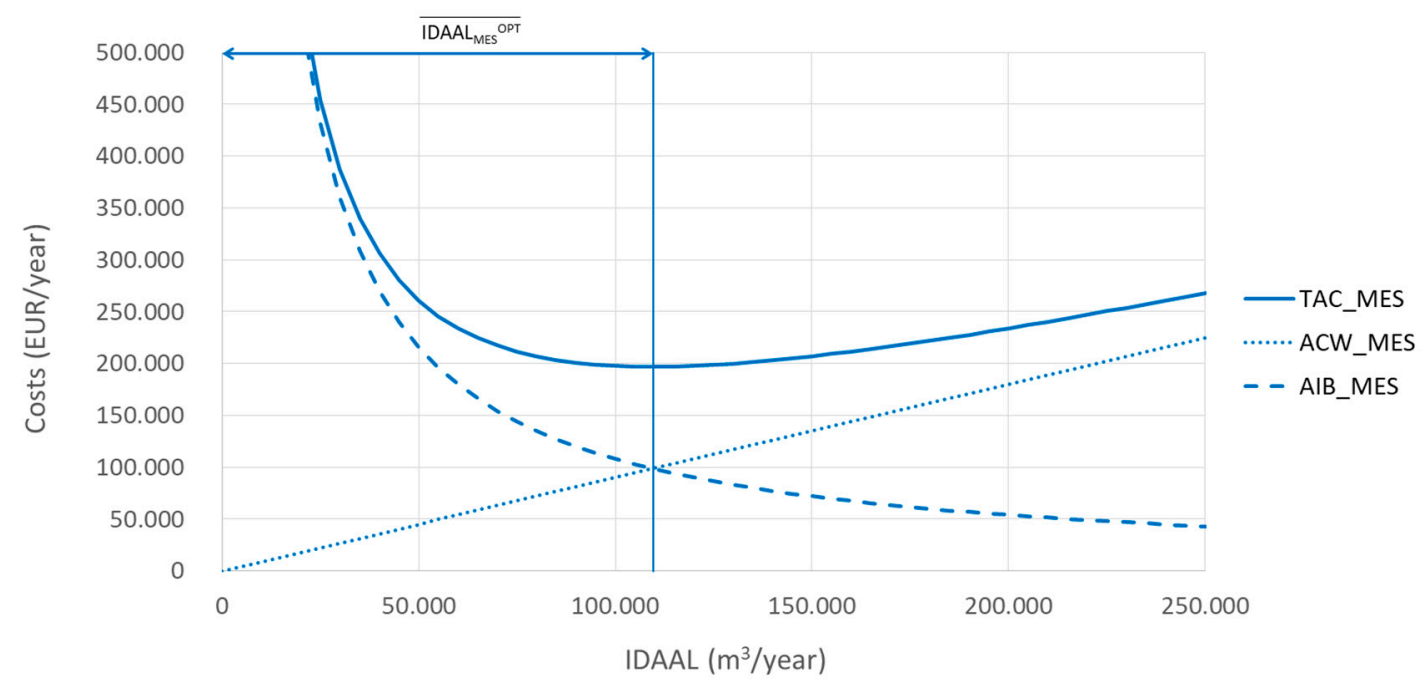

Figure A3. Case study 1 -Cost minimization of $I D A A L_{M E S}$.

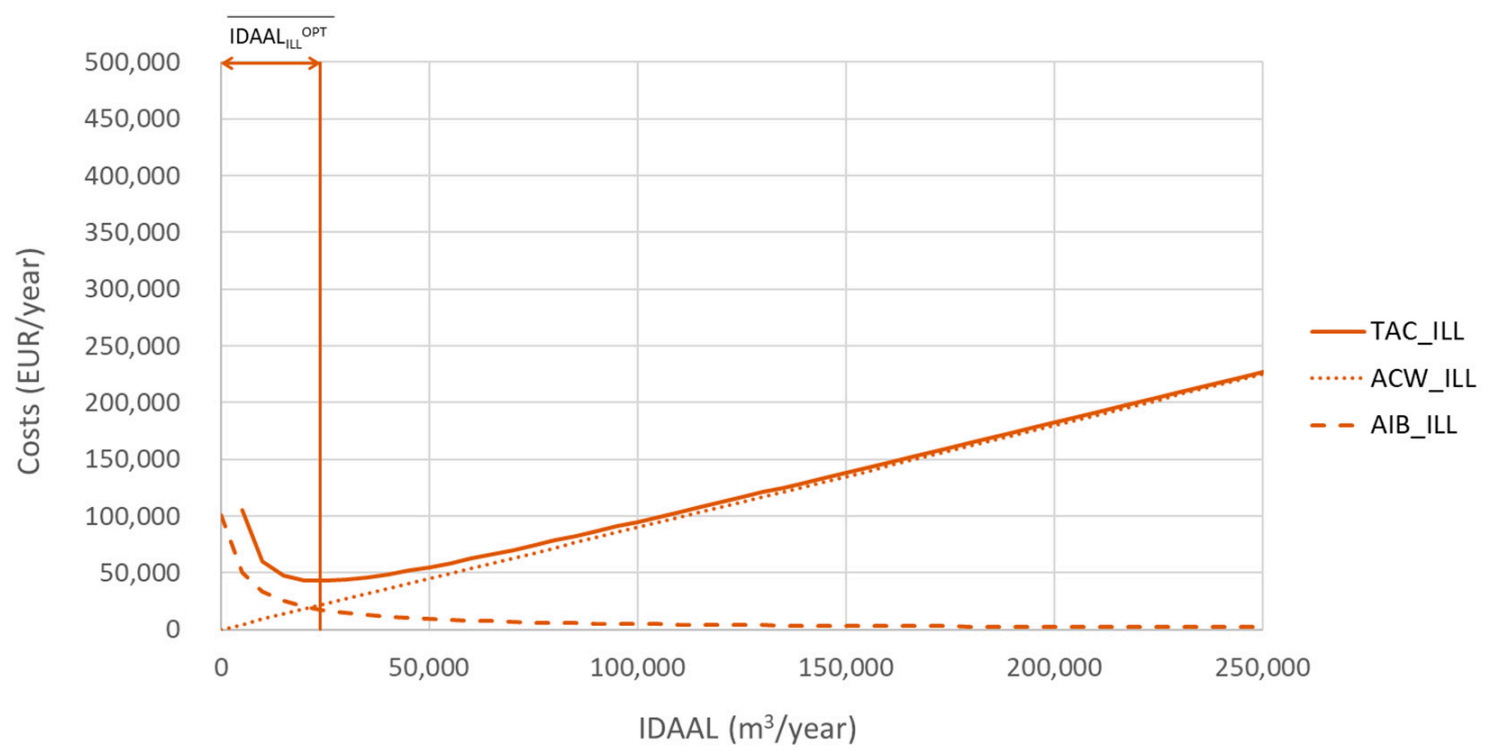

Figure A4. Case study 1 -Cost minimization of $I D A A L_{I L L}$. 
Up to this point, the results for each policy have been obtained independently from each other. Then, the addition of the total values yields the optimized total volume (for the whole utility) of the annual apparent losses (Figure 3):

$$
\overline{I D A A L^{O P T}}=\overline{I D A A L_{M E S}^{O P T}}+\overline{I D A A L_{I L L}^{O P T}}=133,262 \frac{\mathrm{m}^{3}}{\text { year }}
$$

The value of the ELAL for the whole utility turns out to be (Equation (23))

$$
E L A L=I I A A L+\overline{I D A A L^{O P T}}=440,162 \frac{\mathrm{m}^{3}}{\text { year }}
$$

and the resulting minimized total costs are

$$
T A C^{O P T}=T A C_{I L L}^{O P T}+T A C_{I L L}^{O P T}=239,871 \frac{€}{\text { year }}
$$

Figure A5 shows the magnitude of the main components of total apparent losses after minimization: IIAAL that, being independent of the intervention frequencies, it is not affected by the minimization of the cost function. On the contrary, this figure also shows how both $\overline{\operatorname{IDAAL}} \mathrm{IPT}_{M E S}$ and $\overline{I D A A L_{I L L}^{O P T}}$ have been minimized. The same figure shows the total costs curve associated with each of those two policies to demonstrate that the minimum point corresponds, in each case, to the minimized value.

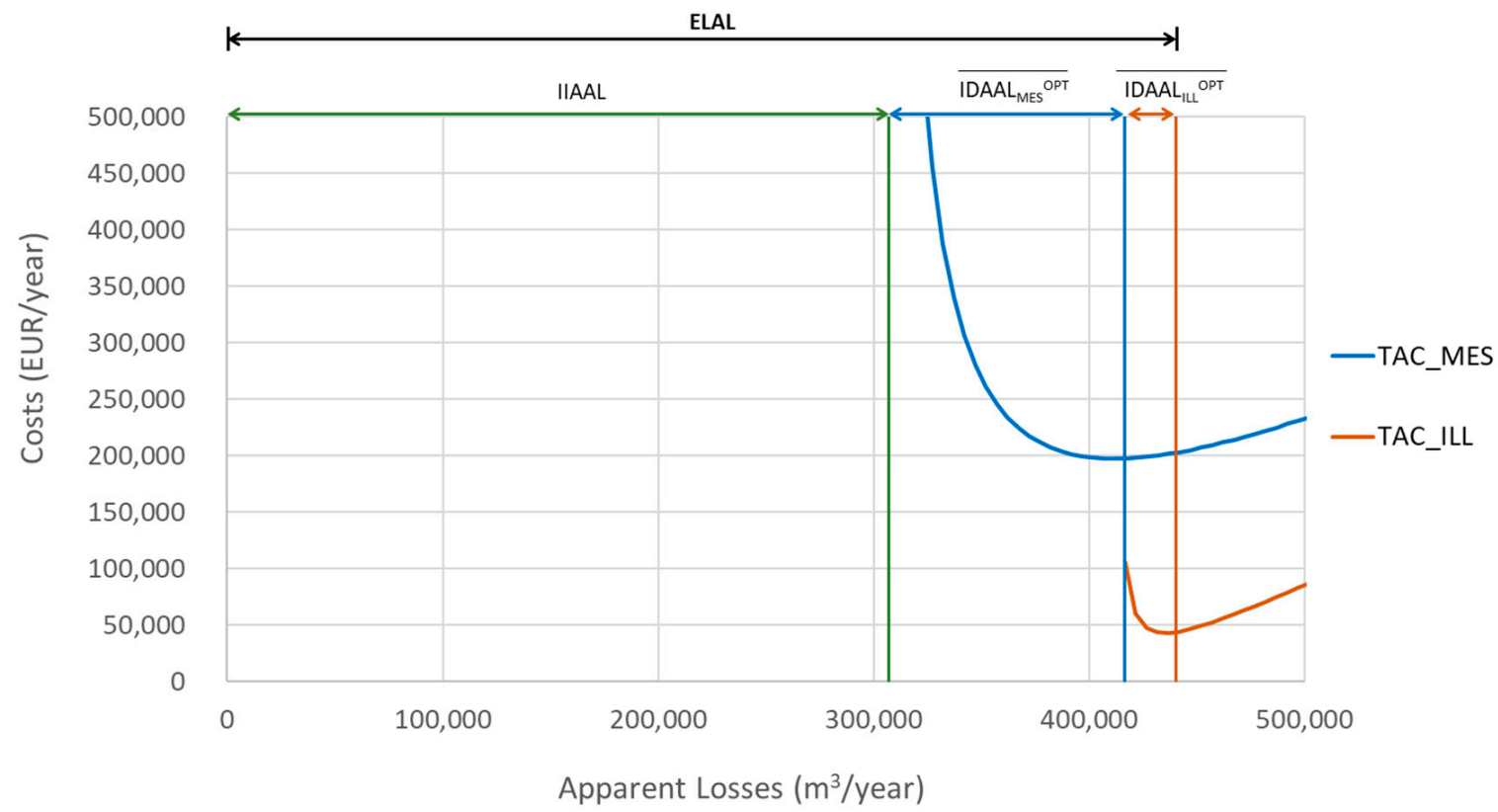

Figure A5. Case study 1 -Final representation of the ELAL value.

As a summary, Table A2 (for volumes) and Table A3 (for costs) show all the numerical results in which key values, current and minimized, have been highlighted in red. Additionally, Table A4 shows the results for the three apparent losses indicators defined in this paper. 
Table A2. Case study 1-Summary of results of apparent losses volumes.

\begin{tabular}{|c|c|c|}
\hline \multirow{5}{*}{$\begin{array}{c}C A A L \\
474,525 \mathrm{~m}^{3} / \text { year }\end{array}$} & \multirow{3}{*}{$\begin{array}{c}\text { IIAAL } \\
306,900 \mathrm{~m}^{3} / \text { year }\end{array}$} & $\begin{array}{c}\text { IIAAL L } \\
288,000 \mathrm{~m}^{3} / \text { year }\end{array}$ \\
\hline & & $\begin{array}{c}\text { IIAAL LILL } \\
13,500 \mathrm{~m}^{3} / \text { year }\end{array}$ \\
\hline & & $\begin{array}{c}\text { IIAAL } \\
5400 \mathrm{~m}^{3} / \text { year }\end{array}$ \\
\hline & $\overline{I D A A L}$ & $\begin{array}{c}\overline{I D A A L_{M E S}} \\
157,500 \mathrm{~m}^{3} / \text { year }\end{array}$ \\
\hline & $167,625 \mathrm{~m}^{3} /$ year & $\begin{array}{c}\overline{I D A A L_{I L L}} \\
10,125 \mathrm{~m}^{3} / \text { year }\end{array}$ \\
\hline \multirow{5}{*}{$\begin{array}{c}\boldsymbol{E L A L} \\
440,162 \mathrm{~m}^{3} / \text { year }\end{array}$} & \multirow{3}{*}{$\begin{array}{c}\text { IIAAL } \\
306,900 \mathrm{~m}^{3} / \text { year }\end{array}$} & $\begin{array}{c}\text { IIAAL } L_{M E S} \\
288,000 \mathrm{~m}^{3} / \text { year }\end{array}$ \\
\hline & & $\begin{array}{c}\text { IIAAL ILL } \\
13,500 \mathrm{~m}^{3} / \text { year }\end{array}$ \\
\hline & & $\begin{array}{c}\text { IIAAL } \\
5400 \mathrm{~m}^{3} / \text { year }\end{array}$ \\
\hline & $\overline{I D A A L^{O P T}}$ & $\begin{array}{c}\overline{I D A A L_{M E S}^{O P T}} \\
109,545 \mathrm{~m}^{3} / \text { year }\end{array}$ \\
\hline & $133,262 \mathrm{~m}^{3} /$ year & $\begin{array}{c}\overline{\text { IDAAL OPT }} \\
23,717 \mathrm{~m}^{3} / \text { year }\end{array}$ \\
\hline
\end{tabular}

Table A3. Case study 1-Summary of results of costs.

\begin{tabular}{|c|c|c|c|c|c|c|c|}
\hline & $\begin{array}{l}A I B_{M E S} \\
\text { (€/year) }\end{array}$ & $\begin{array}{l}A I B_{I L L} \\
\text { (€/year) }\end{array}$ & $\begin{array}{c}A C W_{M E S} \\
\text { (€/year) }\end{array}$ & $\begin{array}{c}A C W_{I L L} \\
\text { (€/year) }\end{array}$ & $\begin{array}{l}T A C_{M E S} \\
\text { (€/year) }\end{array}$ & $\begin{array}{l}\text { TAC } C_{I L L} \\
\text { (€/year) }\end{array}$ & $\begin{array}{c}\text { TAC } \\
\text { (€/year) }\end{array}$ \\
\hline Current & 68,571 & 50,000 & 141,750 & 9113 & 210,321 & 59,113 & 269,434 \\
\hline Minimized & 98,590 & 21,345 & 98,590 & 21,345 & 197,180 & 42,691 & 239,871 \\
\hline
\end{tabular}

Table A4. Case study 1-Apparent loss indicators.

\begin{tabular}{cccc}
\hline Equation & Variable & Calculation & Result \\
\hline$(31)$ & $A L I$ & $\frac{C A A L}{I I A A L}$ & 1.55 \\
\hline$(32)$ & $A L E I$ & $\frac{C A A L}{E L A L}$ & 1.08 \\
\hline$(33)$ & $A L E P I$ & $\frac{E L A L}{I I A A L}$ & 1.43 \\
\hline
\end{tabular}

\section{Appendix A.7. Case Study 1-Conclusions}

The value of ALI shows that the current apparent losses (CAAL) are $55 \%$ greater than the technical minimum achievable value (IIAAL). This indicator is equivalent to the ILI used for real losses. On the other hand, the economic level of apparent losses (ELAL) obtained after the minimization process is still $43 \%$ greater than the technical minimum level, as shown by the ALEPI. So, the improvement expected from the economic minimization is, according to the ALEI, about $8 \%$. This means that the current losses are only $8 \%$ apart from the economic level that and the water utility is close to the expected targets.

The results of the minimization also show the way current apparent loss management policies should be modified. In the first place, the intervention periods should change significantly in comparison to the current ones-a 30\% reduction of the meters replacement period (from 14 to 9.7 years) and $130 \%$ extension of the meters inspection period (from 3 to 7 years). This fact highlights how misleading traditional approaches for these policies can be compared to real accurate approaches. 
As shown by the ALEI, apparent losses could be reduced $8 \%$ after minimization, but that figure refers to the total system apparent losses. If closely considered, the component of apparent losses, once optimized (IDAAL), would yield savings up to $20 \%$.

Finally, the reduction obtained in the total costs is about $9 \%$, which comes unequally from the savings produced by optimizing each policy - a 7\% reduction in costs associated with the optimization of the replacement of meters and a $28 \%$ reduction in costs due to the optimization of the inspection of meters.

\section{Appendix B. Case Study 2-Example for a Water Utility with Complete Data}

\section{Appendix B.1. General Data}

To show the applicability of the economic model herein presented, a complete case study is analysed with two types of meters (velocity and volumetric) and three types of customers (residential, small ICI and medium-large ICI). The data used in this case study has been partially taken from a medium-sized water utility in Spain (Table A5). The total number of users served is over 50,000 and the population of the city is approximately 175,000. The degradation rates used for velocity (single jet) and volumetric meters were derived from the study conducted by Gavara-Tortes [43].

Table A5. Case study 2-General data.

\begin{tabular}{|c|c|c|c|c|}
\hline $\begin{array}{c}\text { USER TYPE } \\
\text { METER TYPE }\end{array}$ & \multicolumn{2}{|c|}{ RESIDENTIAL } & $\begin{array}{l}\text { SMALL ICI } \\
\text { VELOCITY }\end{array}$ & $\begin{array}{c}\text { MEDIUM-LARGE ICI } \\
\text { VELOCITY }\end{array}$ \\
\hline$N M_{i}$ (meters) & 30,000 & 17,250 & 2500 & 250 \\
\hline$\varepsilon_{i}(0)(\%)$ & -5 & -1 & -3 & 0 \\
\hline$A M F F_{i}(\% /$ year $)$ & 0.5 & 0.5 & 0.5 & 0.2 \\
\hline$A D R_{i}(\% /$ year $)$ & 0.5 & 0.5 & 0.3 & 0.1 \\
\hline$A I C R_{j}(\% /$ year $)$ & 0.15 & 0.15 & 0.05 & 0 \\
\hline$T_{M E S i}$ (years) & 14 & 14 & 14 & 14 \\
\hline$T_{I L L j}$ (years) & 3 & 3 & 3 & 3 \\
\hline$U I C_{M E S i}(€ /$ meter $)$ & 32 & 37 & 62 & 400 \\
\hline
\end{tabular}

Appendix B.2. IIAAL-(Current) Intervention Independent Annual Apparent Losses

The IIAAL has three different components. The calculation of the first one, due to meter measuring inaccuracies, relies on the value $U A U V$ (Equation (1)):

$$
U A U V=(-1) \times \sum_{i}\left(\varepsilon_{i}(0) \times A C V_{i}\right)=288,375 \frac{\mathrm{m}^{3}}{\text { year }}
$$

and also on the value of $A D M F A L$ (Equation (3)):

$$
A D M F A L=\sum_{i}\left(A M F F_{i} \times A C V_{i} \times A R T_{i}\right)=29,481 \frac{\mathrm{m}^{3}}{\text { year }}
$$

Therefore, the first component of $I I A A L$ results in (Equation (4))

$$
I I A A L_{M E S}=I C F \times U A U V+A D M F A L=378,415 \frac{\mathrm{m}^{3}}{\text { year }}
$$


The second component, due to illegal consumption, is calculated through (Equation (5))

$$
I I A A L_{I L L}=\sum_{j}\left(A I F_{j} \times A C V_{j}\right)=26,263 \frac{\mathrm{m}^{3}}{\text { year }}
$$

In third place, the apparent losses caused by data handling are (Equation (6))

$$
I I A A L_{D H}=D H E \times \sum_{i}\left(N M_{i}\right)=9000 \frac{\mathrm{m}^{3}}{\text { year }}
$$

Finally, the value of IIAAL can be calculated as the sum of the three components already obtained (Figure 3):

$$
I I A A L=I I A A L_{M E S}+I I A A L_{I L L}+I I A A L_{D H}=413,478 \frac{\mathrm{m}^{3}}{\text { year }}
$$

Appendix B.3. IDAAL—(Current) Intervention Dependent Annual Apparent Losses

The IDAAL has two components. The calculation of the first one, due to meter measuring inaccuracies, begins by solving the NRRAL $L_{M E S_{i}}$ and $\overline{I D A A L_{M E S_{i}}}$ for each type meter $i$. Results are

\begin{tabular}{|c|c|c|c|c|c|c|}
\hline \multirow{3}{*}{ Equation } & \multirow{3}{*}{ Variable } & \multirow{3}{*}{ Calculation } & \multicolumn{4}{|c|}{ Type of Customer/Type of Meter } \\
\hline & & & \multicolumn{2}{|c|}{ Residential } & \multirow{2}{*}{$\begin{array}{c}\text { Small ICI } \\
\text { Velocity }\end{array}$} & \multirow{2}{*}{$\begin{array}{c}\text { Med-Large ICI } \\
\text { Velocity }\end{array}$} \\
\hline & & & Velocity & Volumetric & & \\
\hline$(8)$ & $N R R A L_{M E S_{i}}$ & $A D R_{i} / 100 \times A C V_{i}$ & 22,500 & 12,938 & 3750 & 750 \\
\hline$(13)$ & $\overline{I D A A L_{M E S_{i}}}$ & $\frac{1}{2} N R A A L_{M E S_{i}} \times T_{M E S_{i}}$ & 157,500 & 90,563 & 26,250 & 5250 \\
\hline
\end{tabular}
shown in Table A6.

Table A6. Case study 2-Current values of $\overline{I D A A L_{M E S}}$.

So, the total value of current $\overline{I D A A L_{M E S}}$, for all the meter types is

$$
\overline{I D A A L_{M E S}}=\sum_{i} \overline{I D A A L_{M E S}}=279,563 \frac{\mathrm{m}^{3}}{\text { year }}
$$

\begin{tabular}{|c|c|c|c|c|c|}
\hline \multirow{2}{*}{ Equation } & \multirow{2}{*}{ Variable } & \multirow{2}{*}{ Calculation } & \multicolumn{3}{|c|}{ Type of Customer } \\
\hline & & & Residential & Small ICI & Med-Large ICI \\
\hline (11) & $N R R A L_{I L L_{j}}$ & $A I C R_{j} / 100 \times A C V_{j}$ & 10,631 & 625 & - \\
\hline (14) & $\overline{I D A L_{I L L_{j}}}$ & $\frac{1}{2} N R R A L_{I L L_{j}} \times T_{I L L_{j}}$ & 15,947 & 938 & - \\
\hline
\end{tabular}

In a parallel way, the second component, associated with illegal consumption, can be obtained through $N R R A L_{I L L_{j}}$ and $\overline{I D A A L_{I L L_{j}}}$, as shown in Table A7.

Table A7. Case study $2-$ Current values of $\overline{I D A A L_{I L L_{j}}}$.

So, the total value of current $\overline{I D A A L_{I L L}}$, for all the meter types is

$$
\overline{I D A A L_{I L L}}=\sum_{j} \overline{I D A A L_{I L L_{j}}}=16,884 \frac{\mathrm{m}^{3}}{\text { year }}
$$

Finally, the total value of $\overline{I D A A L}$ can be calculated as the sum of the two components already obtained (Figure 3):

$$
\overline{I D A A L}=\overline{I D A A L_{M E S}}+\overline{I D A A L_{I L L}}=296,447 \frac{\mathrm{m}^{3}}{\text { year }}
$$


Appendix B.4. CAAL—Current Annual Apparent Losses

The total current annual apparent losses, $C A A L$, are obtained by adding the two categories calculated in the previous sections (Figure 3):

$$
C A A L=I I A A L+\overline{I D A A L}=710,124 \frac{\mathrm{m}^{3}}{\text { year }}
$$

\section{Appendix B.5. TAC-Total Annual Costs of Current Control Policies}

To calculate the total costs of each policy (meters replacement and meters inspection), successive variables $T I C, A I B, A C W$, and $T A C$ must be obtained (depending on each type of meter or customer, respectively). Table A8 shows the results for the policy for replacing meters, focused on managing the ageing of meters:

Table A8. Case study 2-Current values of costs for the first policy.

\begin{tabular}{|c|c|c|c|c|c|c|}
\hline \multirow{3}{*}{ Equation } & \multirow{3}{*}{ Variable } & \multirow{3}{*}{ Calculation } & \multicolumn{4}{|c|}{ Type of Customer/Type of Meter } \\
\hline & & & \multicolumn{2}{|c|}{ Residential } & \multirow{2}{*}{$\frac{\text { Small ICI }}{\text { Velocity }}$} & \multirow{2}{*}{$\begin{array}{c}\text { Med-Large ICI } \\
\text { Velocity }\end{array}$} \\
\hline & & & Velocity & Volumetric & & \\
\hline- & $T I C_{M E S_{i}}$ & $U I C_{M E S \_i} \times N M_{i}$ & 960,000 & 638,250 & 155,000 & 100,000 \\
\hline$(15)$ & $A I B_{M E S_{i}}$ & $\frac{T_{I I C_{M E S}}}{T_{M E S_{i}}}$ & 68,571 & 45,589 & 11,071 & 7143 \\
\hline$(17)$ & $A C W_{M E S_{i}}$ & $P W \times \overline{I D A A L_{M E S_{i}}}$ & 141,750 & 81,506 & 23,625 & 4725 \\
\hline (19) & $T A C_{M E S_{i}}$ & $A I B_{M E S_{i}}+A C W_{M E S_{i}}$ & 210,321 & 127,096 & 34,696 & 11,868 \\
\hline
\end{tabular}

The total added costs are

$$
T A C_{M E S}=\sum_{i} T A C_{M E S_{i}}=383,981 \frac{€}{\text { year }}
$$

Different costs associated with the meters inspection policy, focused on managing illegal water uses, are shown in Table A9:

Table A9. Case study 2-Current values of costs for the second policy.

\begin{tabular}{cccccc}
\hline \multirow{2}{*}{ Equation } & \multirow{2}{*}{ Variable } & \multirow{2}{*}{ Calculation } & \multicolumn{3}{c}{ Type of Customer } \\
\cline { 3 - 5 } & & & Residential & Small ICI & Med-Large ICI \\
\hline- & $T I C_{I L L_{j}}$ & $U I C_{I L L j} \times N M_{j}$ & 236,250 & 12,500 & 12,500 \\
$(16)$ & $A I B_{I L L_{j}}$ & $\frac{T I C_{I L L_{j}}}{T_{I L L_{j}}}$ & 78,750 & 4167 & 4167 \\
$(18)$ & $A C W_{I L L_{j}}$ & $P W \times \frac{I D A L_{I L L_{j}}}{I D n}$ & 14,352 & 844 & 0 \\
$(20)$ & $T A C_{I L L_{j}}$ & $A I B_{I L L_{j}}+A C W_{I L L_{j}}$ & 93,102 & 5010 & 4167 \\
\hline
\end{tabular}

The total added costs are

$$
T A C_{I L L}=\sum_{j} T A C_{I L L_{j}}=102,279 \frac{€}{\text { year }}
$$

Finally, the total added costs of both current policies are

$$
T A C=T A C_{M E S}+T A C_{I L L}=486,261 \frac{€}{\text { year }}
$$

Appendix B.6. ELAL-Control Policies Frequency and the Economic Level of Apparent

As explained above, both policies and each component within each policy should be optimized independently of each other. The economic level of losses, intervention period, and the annual percentage of meters replaced every year, are shown in Table A10: 
Table A10. Case study 2-The first policy parameters after minimization.

\begin{tabular}{|c|c|c|c|c|c|c|}
\hline \multirow{3}{*}{ Equation } & \multirow{3}{*}{ Variable } & \multirow{3}{*}{ Calculation } & \multicolumn{4}{|c|}{ Type of Customer/Type of Meter } \\
\hline & & & \multicolumn{2}{|c|}{ Residential } & \multirow{2}{*}{$\frac{\text { Small ICI }}{\text { Velocity }}$} & \multirow{2}{*}{$\frac{\text { Med-Large ICI }}{\text { Velocity }}$} \\
\hline & & & Velocity & Volumetric & & \\
\hline (21) & $\overline{I D A A L_{M E S_{i}}^{O P T}}$ & $\sqrt{\frac{T I C_{M E S_{i}} \times N R R A L_{M E S_{i}}}{2 \times P W}}$ & 109,545 & 67,731 & 17,970 & 6455 \\
\hline (27) & $T_{M E S_{i}}^{O P T}$ & $\sqrt{\frac{2 \times T I C_{M E S_{i}}}{N R R A L_{M E S_{i}} \times P W}}$ & 9.74 & 10.47 & 9.58 & 17.21 \\
\hline (29) & $P A I M_{M E S_{i}}^{O P T}$ & $\frac{1}{T_{M E S_{i}}^{O P P}} \times 100$ & $10.3 \%$ & $9.6 \%$ & $10.4 \%$ & $5.8 \%$ \\
\hline
\end{tabular}

The resulting costs are shown in Table A11.

Table A11. Case study 2-The first policy costs after minimization.

\begin{tabular}{|c|c|c|c|c|c|c|}
\hline \multirow{3}{*}{ Equation } & \multirow{3}{*}{ Variable } & \multirow{3}{*}{ Calculation } & \multicolumn{4}{|c|}{ Type of Customer/Type of Meter } \\
\hline & & & \multicolumn{2}{|c|}{ Residential } & \multirow{2}{*}{$\frac{\text { Small ICI }}{\text { Velocity }}$} & \multirow{2}{*}{$\frac{\text { Med-Large ICI }}{\text { Velocity }}$} \\
\hline & & & Velocity & Volumetric & & \\
\hline (15) & $A I B_{M E S_{i}}^{O P T}$ & $\frac{\operatorname{TIC}_{M E S_{i}}}{T_{M E S_{i}}^{O P P T}}$ & 98,590 & 60,957 & 16,173 & 5809 \\
\hline (17) & $A C W_{M E S_{i}}^{O P T}$ & $P W \times \overline{I D A A L_{M E S}^{O P T}}$ & 98,590 & 60,957 & 16,173 & 5809 \\
\hline (19) & $\mathrm{TAC}_{M E S_{i}}^{O P T_{i}}$ & $A I B_{M E S_{i}}^{O P T}+A C W_{M E S_{i}}^{O P P T}$ & 197,180 & 121,915 & 32,346 & 11,619 \\
\hline
\end{tabular}

and the total optimized costs are

$$
T A C_{M E S}^{O P T}=\sum_{i} T A C_{M E S_{i}}^{O P T}=363,060 \frac{€}{\text { year }}
$$

In parallel, the optimized (minimum) losses volume, intervention period, and the annual percentage of inspected meters for the meters inspection policy are shown in Table A12.

Table A12. Case study 2-The second policy parameters after minimization.

\begin{tabular}{|c|c|c|c|c|c|}
\hline \multirow{2}{*}{ Equation } & \multirow{2}{*}{ Variable } & \multirow{2}{*}{ Calculation } & \multicolumn{3}{|c|}{ Type of Customer } \\
\hline & & & Residential & Small ICI & Med-Large ICI \\
\hline$(22)$ & $\overline{I D A A L_{I L L_{j}}^{O P T}}$ & $\sqrt{\frac{T I C_{I L L_{j}} \times N R R A L_{I L L_{j}}}{2 \times P W}}$ & 37,354 & 2083 & - \\
\hline$(28)$ & $T_{I L L_{j}}^{O P T}$ & $\sqrt{\frac{2 \times T I C_{I L L_{j}}}{\text { NRRAL }_{I L L_{j}} \times P W}}$ & 7.03 & 6.67 & - \\
\hline$(30)$ & $P A I M_{I L L_{j}}^{O P T}$ & $\frac{1}{T_{I L L_{j}}^{O P T}} \times 100$ & $14.2 \%$ & $15.0 \%$ & - \\
\hline
\end{tabular}

The resulting different costs are shown in Table A13.

Table A13. Case study 2-The second policy costs after minimization.

\begin{tabular}{cccccc}
\hline \multirow{2}{*}{ Equation } & \multirow{2}{*}{ Variable } & \multirow{2}{*}{ Calculation } & \multicolumn{3}{c}{ Type of Customer } \\
\cline { 3 - 5 } & & Residential & Small ICI & Med-Larg ICI \\
\hline \multirow{2}{*}{$(16)$} & $A I B_{I L L_{j}}^{O P T}$ & $\frac{T I C_{I L L_{j}}}{T_{I L L_{j}}}$ & 33,619 & 1875 & - \\
$(18)$ & $A C W_{I L L_{j}}^{O P T}$ & $P W \times \frac{I D A A L_{I L L_{j}}^{O P T}}{20}$ & 33,619 & 1875 & - \\
$(20)$ & $T A C_{I L L_{j}}^{O P T}$ & $A I B_{I L L_{j}}^{O P T}+A C W_{I L L_{j}}^{O P T}$ & 67,238 & 3750 & - \\
\hline
\end{tabular}


And the total minimized costs are

$$
T A C_{I L L}^{O P T}=\sum_{j} T A C_{I L L_{j}}^{O P T}=70,988 \frac{€}{\text { year }}
$$

Up to this point, the results for each policy have been obtained in an independent way from each other. Now, the addition of those total values results in the optimized total volume (for the whole utility) of annual apparent losses is (Figure 3)

$$
\overline{I D A A L^{O P T}}=\overline{I D A A L_{M E S}^{O P T}}+\overline{I D A A L_{I L L}^{O P T}}=241,138 \frac{\mathrm{m}^{3}}{\text { year }}
$$

Finally, the value of the ELAL for the whole utility turns out to be (Equation (23))

$$
E L A L=I I A A L+\overline{I D A A L^{O P T}}=654,815 \frac{\mathrm{m}^{3}}{\text { year }}
$$

and the resulting minimized total costs are

$$
T A C^{O P T}=T A C_{I L L}^{O P T}+T A C_{I L L}^{O P T}=434,048 \frac{€}{\text { year }}
$$

As a summary, Table A14 (for volumes) and Table A15 (for costs) show all the numerical results

\begin{tabular}{|c|c|c|}
\hline \multirow{5}{*}{$\begin{array}{c}C A A L \\
710,124 \mathrm{~m}^{3} / \text { year }\end{array}$} & \multirow{3}{*}{$\begin{array}{c}\text { IIAAL } \\
413,678 \mathrm{~m}^{3} / \text { year }\end{array}$} & $\begin{array}{c}\text { IIAAL } \\
378,415 \mathrm{~m}^{3} / \text { year }\end{array}$ \\
\hline & & $\begin{array}{c}\text { IIAALLILL } \\
26,263 \mathrm{~m}^{3} / \text { year }\end{array}$ \\
\hline & & $\begin{array}{c}\text { IIAAL } L_{D H} \\
9000 \mathrm{~m}^{3} / \text { year }\end{array}$ \\
\hline & $\overline{I D A A L}$ & $\begin{array}{c}\overline{I D A A L_{M E S}} \\
279,563 \mathrm{~m}^{3} / \text { year }\end{array}$ \\
\hline & $296,447 \mathrm{~m}^{3} /$ year & $\begin{array}{c}\overline{I D A A L_{I L L}} \\
16,884 \mathrm{~m}^{3} / \text { year }\end{array}$ \\
\hline \multirow{5}{*}{$\begin{array}{c}E L A L \\
654,815 \mathrm{~m}^{3} / \text { year }\end{array}$} & \multirow{3}{*}{$\begin{array}{c}\text { IIAAL } \\
413,678 \mathrm{~m}^{3} / \text { year }\end{array}$} & $\begin{array}{c}\text { IIAAL } \\
378,415 \mathrm{~m}^{3} / \text { year }\end{array}$ \\
\hline & & $\begin{array}{c}\text { IIAALLILL } \\
26,263 \mathrm{~m}^{3} / \text { year }\end{array}$ \\
\hline & & $\begin{array}{c}I I A A L_{D H} \\
9000 \mathrm{~m}^{3} / \text { year }\end{array}$ \\
\hline & $\overline{I D A A L^{O P T}}$ & $\begin{array}{c}\overline{I D A A L_{M E S}^{O P T}} \\
201,700 \mathrm{~m}^{3} / \text { year }\end{array}$ \\
\hline & $241,138 \mathrm{~m}^{3} /$ year & $\begin{array}{c}\overline{I D A A L_{I L L}^{O P T}} \\
39,438 \mathrm{~m}^{3} / \text { year }\end{array}$ \\
\hline
\end{tabular}
in which key values, current and optimized, have been highlighted in red. Additionally, Table A16 shows the results for the three apparent losses indicators defined in this paper.

\begin{tabular}{|c|c|c|c|c|c|c|c|}
\hline & $\begin{array}{l}A I B_{M E S} \\
\text { (€/year) }\end{array}$ & $\begin{array}{c}A I B_{I L L} \\
\text { (€/year) }\end{array}$ & $\begin{array}{c}A C W_{M E S} \\
\text { (€/year) }\end{array}$ & $\begin{array}{c}A C W_{I L L} \\
\text { (€/year) }\end{array}$ & $\begin{array}{l}\text { TAC } C_{M E S} \\
\text { (€/year) }\end{array}$ & $\begin{array}{l}T A C_{I L L} \\
\text { (€/year) }\end{array}$ & $\begin{array}{c}\text { TAC } \\
\text { (€/year) }\end{array}$ \\
\hline Current & 132,375 & 87,083 & 251,606 & 15,196 & 383,981 & 102,279 & 486,261 \\
\hline Minimized & 181,560 & 35,494 & 181,530 & 35,494 & 363,060 & 70,988 & 434,048 \\
\hline
\end{tabular}

Table A14. Case study 2-Summary of the results of the apparent loss volumes.

Table A15. Case study 2-Summary of the results of the costs. 
Table A16. Case study 2-Apparent loss indicators.

\begin{tabular}{cccc}
\hline Equation & Variable & Calculation & Result \\
\hline$(31)$ & $A L I$ & $\frac{C A A L}{I I A A L}$ & 1.72 \\
\hline$(32)$ & $A L E I$ & $\frac{C A A L}{E L A L}$ & 1.09 \\
\hline$(33)$ & $A L E P I$ & $\frac{E L A L}{I I A A L}$ & 1.58 \\
\hline
\end{tabular}

Appendix B.7. ELAL—Sensitivity Analysis

Most of the data used in the calculations to obtain the ELAL are easily available: the price of water, meter replacement and customers' connection inspection costs, number of meters and connections, etc. However, the same may not be true for the Annual Degradation Rate, $A D R_{i}$, of each meter type $i$. Unless water meter samples are regularly tested by the utility and a well-defined procedure is established to assess meter ageing, the actual magnitude of $A D R_{i}$ can be uncertain. Similarly, the Annual Illegal Consumption Increasing Rate, $A I C R_{j}$, for each customer type $j$, is also an uncertain parameter.

In order to assess the impact related to the estimation uncertainties of parameters used in the ELAL calculation, a sensitivity analysis has been conducted for this particular case study. The sensitivity analysis considers the uncertainties in the estimation of the $A D R_{i}$ of the $4 \mathrm{~m}$ types identified and also for the overall NRRAL $L_{M E S_{i}}$ (Equation (8)). These parameters affect the $\overline{I D A A L}_{M E S_{i}}^{O P T}$ (Equation (21)). A similar procedure has been followed to assess the impact of the $A I C R_{j}, N R R A L_{I L L_{j}}$, and $\overline{I D A A L}_{I L L_{j}}^{O P T}$ (Equations (11), (22), and (23)).

Figure A6 shows the graphical results of the sensitivity analysis. The resulting ELAL does not vary more than $10 \%$ even for changes in the input variables of up to $50 \%$. In the worst-case scenario, with the $50 \%$ error in any of the seven variables considered, the variation of the $E L A L$ roughly reaches $10 \%$. With the $50 \%$ error in all four $A D R_{i}$, the resulting $E L A L$ variation is less than $10 \%$. The highest impact of one individual $A D R_{i}$, the one corresponding to velocity meters of residential customers, is less than $5 \%$.

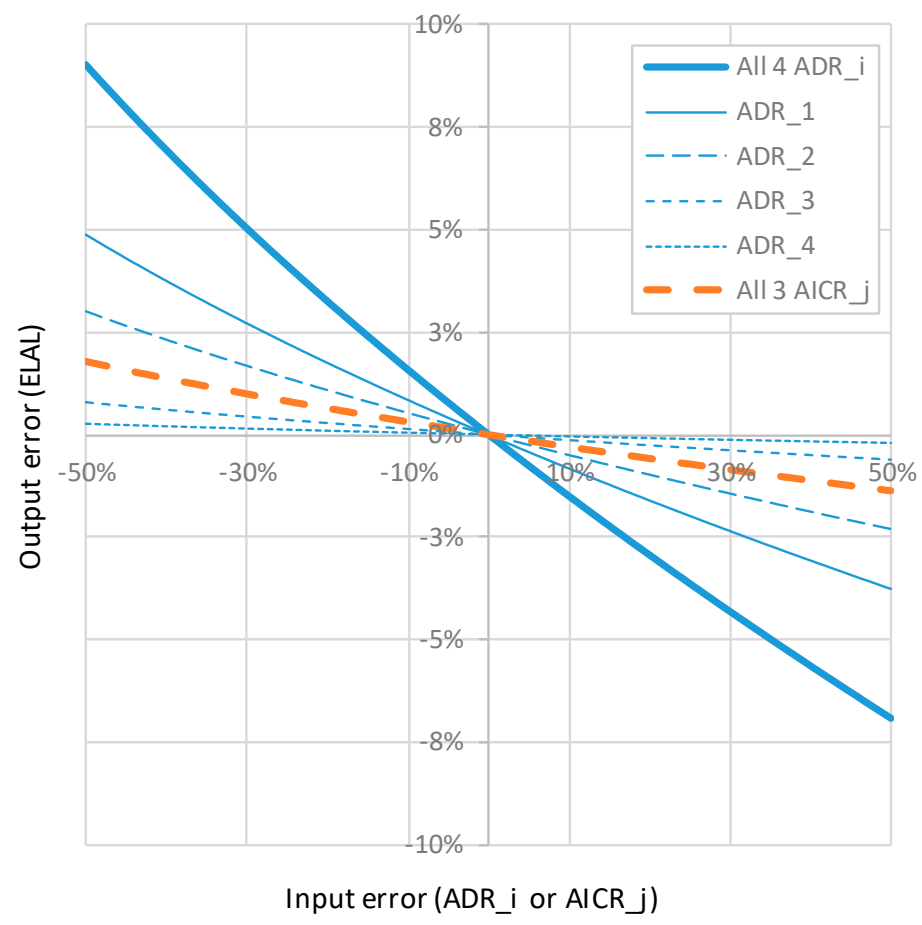

Figure A6. Case study 2-Sensitivity analysis of ELAL results. 
Appendix B.8. Case Study 2-Conclusions

The value of the ALI shows that current apparent losses (CAAL) are $72 \%$ greater than the technical minimum value (IIAAL). Furthermore, the economic level (ELAL) obtained after the minimization process is still $58 \%$ greater than the technical minimum level, as shown by the ALEPI. The improvement range that can be achieved by the economic minimization is, according to the ALEI, about $9 \%$.

The results of the minimization also show in which way current apparent losses management policies should be modified. In the first place, the optimized intervention periods have significantly changed in comparison to the initial values. In general, optimized meter replacement periods are shorter and optimized meter inspection periods become longer. However, after the calculation of the economic level of losses, some differences need to be highlighted. While the inspection period for customer connections more than doubles for both user types, replacement periods are shorter by about $30 \%$ in three of the four cases; the optimized replacement time for the fourth one (medium-large ICI) turns out to be longer than the initial value by $25 \%$.

As shown by the ALEI, apparent losses could be reduced by $9 \%$ after the optimization, but that figure refers to the total system apparent losses. If carefully analysed, the component of apparent losses that has been optimized (IDAAL) would show a greater decrease, up to $20 \%$.

Finally, a reduction of more than $10 \%$ of the total costs can be achieved. This reduction comes unequally from the savings produced by optimizing the intervention period of each policy: $6 \%$ reduction costs in meter replacement optimization and $31 \%$ reduction costs in meter inspection optimization. 
Appendix C. The comparison Between the Variables Used for Calculating the Economic Level of Real Losses vs. Apparent Losses

\begin{tabular}{|c|c|c|c|}
\hline \multirow{2}{*}{ Variable } & \multirow{2}{*}{$\begin{array}{l}\text { Calculation of the Economic Level } \\
\text { of REAL Losses (ELL) }\end{array}$} & \multicolumn{2}{|c|}{ Calculation of the Economic Level of APPARENT Losses (ELAL) } \\
\hline & & Apparent Losses Due to Meter Ageing & Apparent Losses Due to Illegal Consumption \\
\hline Growing trend of losses with time & $\begin{array}{l}\text { Natural Rate of Rise of Leakage } \\
\qquad(N R R L)\end{array}$ & $\begin{array}{l}\text { Natural Rise of Apparent Losses due to } \\
\text { meter ageing }\left(N R R A L_{M E S_{i}}\right)\end{array}$ & $\begin{array}{l}\text { Natural Rise of Apparent Losses due to illegal } \\
\text { consumption }\left(N R R A L_{I L L_{j}}\right)\end{array}$ \\
\hline $\begin{array}{l}\text { Intervention to reduce current losses to } \\
\text { their initial value }\end{array}$ & Pipe inspection & Meter replacement & Meter/Connection inspection \\
\hline Unit intervention cost & Pipe inspection cost $(C I)$ & Meter replacement cost $\left(U I C_{M E S_{i}}\right)$ & Meter/Connection inspection cost $\left(U I C_{I L L_{j}}\right)$ \\
\hline Annual intervention cost & $\begin{array}{l}\text { Annual budget for intervention } \\
\qquad(A B I)\end{array}$ & $\begin{array}{l}\text { Annual intervention (replacement) } \\
\text { budget }\left(A I B_{M E S_{i}}\right)\end{array}$ & $\begin{array}{l}\text { Annual intervention (inspection) budget } \\
\qquad\left(A I B_{I L L_{j}}\right)\end{array}$ \\
\hline Unit water value & Marginal cost of supply (MCS) & Price of water $(P W)$ & Price of water $(P W)$ \\
\hline \multirow[t]{2}{*}{ Total annual costs } & \multirow[t]{2}{*}{ Total annual costs $(C T)$} & $\begin{array}{l}\text { Total annual intervention (replacement) } \\
\text { costs }\left(T A C_{M E S_{i}}\right)\end{array}$ & $\begin{array}{l}\text { Total annual intervention (inspection) costs } \\
\qquad\left(T A C_{I L L_{j}}\right)\end{array}$ \\
\hline & & \multicolumn{2}{|c|}{ Total annual intervention cost $(T A C)$} \\
\hline Optimized intervention time period & Economic inspection frequency $(E I F)$ & $\begin{array}{c}\text { Optimum intervention (replacement) } \\
\text { period }\left(T_{M E S_{i}}^{O P T}\right)\end{array}$ & $\begin{array}{l}\text { Optimum intervention (inspection) period } \\
\qquad\left(T_{I L L_{j}}^{O P T}\right)\end{array}$ \\
\hline Economic level of losses & Economic level of real losses $(E L L)$ & \multicolumn{2}{|c|}{ Economic level of apparent losses $(E L A L)$} \\
\hline Main indicator on losses level & Infrastructure leakage level (ILI) & \multicolumn{2}{|c|}{ Apparent losses indicator $(A L I)$} \\
\hline
\end{tabular}




\section{References}

1. Lambert, A.; Hirner, W. Losses from Water Supply Systems: Standard Terminology and Recommended Performance Measures; IWA Blue Pages; 2000; Available online: https://www.researchgate.net/publication/284884240_ Losses_from_water_supply_systems_Standard_terminology_and_recommended_performance_measures (accessed on 7 December 2018).

2. Farley, M.; Trow, S. Losses in Water Distribution Networks: A Practitioner's Guide to Assessment, Monitoring and Control; IWA Publication: London, UK, 2003.

3. Lambert, A. Assessing non-revenue water and its components: A practical approach. Water 21 Mag. Int. Water Assoc. 2003, 5, 50-51.

4. Arregui, F.J.; Cabrera, E.J.; Cobacho, R.; García-Serra, J. Key factors affecting water meter accuracy. In Proceedings of the IWA Leakage Conference 'Leakage 2005', Halifax, NS, Canada, 12-14 September 2005. [CrossRef]

5. Fontanazza, C.M.; Notaro, V.; Puleo, V.; Freni, G. The apparent losses due to metering errors: A proactive approach to predict losses and schedule maintenance. Urban Water J. 2015, 12, 229-239. [CrossRef]

6. Lambert, A.O.; Brown, T.G.; Takizawa, M.; Weimer, D. A review of performance indicators for real losses from water supply systems. J. Water Supply Res. Technol. AQUA 1999, 48, 227-237. [CrossRef]

7. Canto Ríos, J.; Santos-Tellez, R.U.; Hansen Rodríguez, P.; Antúnez Leyva, E.; Nava Martínez, V. Methodology for the identification of apparent losses in water distribution networks. Procedia Eng. 2014, 70, $238-247$. [CrossRef]

8. Rizzo, A. Apparent Water Loss Control: Theory and Application. In Proceedings of the Water Conference, Ferrara, Italy, 17-19 May 2006.

9. Mutikanga, H.E.; Sharma, S.K.; Vairavamoorthy, K. Assessment of apparent losses in urban water systems. Water Environ. J. 2011, 25, 327-335. [CrossRef]

10. Thornton, J.; Sturm, R.; Kunkel, G.A. Water Loss Control; McGraw-Hill: New York, NY, USA, 2008.

11. Kingdom, B.; Liemberger, R.; Marin, P. The Challenge of Reducing Non-Revenue Water (NRW) in Developing Countries. How the Private Sector Can Help: A Look at Performance-Based Service Contracting; Water \& Sanitation Discussion Paper No. 8; World Bank Group: Washington, DC, USA, 2006.

12. Lambert, A.; Charalambous, B.; Fantozzi, M.; Kovac, J.; Rizzo, A.; St John, S.G. 14 Years Experience of using IWA Best Practice Water Balance and Water Loss Performance Indicators in Europe. In Proceedings of the IWA Specialized Conference: Water Loss, Vienna, Austria, 30 April-2 May 2014.

13. Alkasseh, J.M.A.; Adlan, M.N.; Abustan, I.; Hanif, A.B.M. Achieving an economic leakage level in Kinta Valley, Malaysia. Water Utility J. 2015, 11, 31-47.

14. Wyatt, A.; Alshafey, M. Non-revenue water: Financial model for optimal management in developing countries-Application in Aqaba, Jordan. Water Sci. Technol. Water Supply 2012, 12, 451-462. [CrossRef]

15. Trochez-Muñoz, C.; Smout, I.; Kayaga, S. Incorporating energy use into the economic level of Leakage Model. In Proceedings of the World Wide Workshop for Young Environmental Scientists, Arcueil, France, 31 May-4 June 2010.

16. Munoz-Trochez, C. Inclusion of Energy Externalities in the Economic Level of Leakage (ELL) Model. Ph.D. Thesis, Loughborough University, Loughborough, UK, 2011.

17. Rimeika, M.; Albrektienè, R. Reduction of Apparent Water Losses. In Proceedings of the 10th International Conference "Environmental Engineering", Vilnius, Lithuania, 27-28 April 2017.

18. Criminisi, A.; Fontanazza, C.M.; Freni, G.; La Loggia, G. Evaluation of the apparent losses caused by water meter under-registration in intermittent water supply. Water Sci. Technol. 2009, 60, 2373-2382. [CrossRef] [PubMed]

19. Fontanazza, C.M.; Freni, G.; La Loggia, G. Implementation of a Numerical Model for the Evaluation of Potential Apparent Losses in a Distribution Network. In Proceedings of the 5th IWA Water Loss Reduction Specialist Conference, Cape Town, South Africa, 26-30 April 2009; pp. 381-389.

20. Rizzo, A.; Cilia, J. Quantifying meter under-registration caused by the ball valves of roof tanks (for indirect plumbing systems). In Proceedings of the IWA Leakage Conference 'Leakage 2005', Halifax, NS, Canada, 12-14 September 2005. 
21. Arregui, F.J.; Palau, C.V.; Gascón, L.; Peris, O. Evaluating domestic water meter accuracy. A case study. In Pumps, Electromechanical Devices and Systems Applied to Urban Water Management; Swets \& Zeitlinger B.V.: Leiden, The Netherlands, 2003.

22. Xin, K.; Tao, T.; Lu, Y.; Xiong, X.; Li, F. Apparent losses analysis in district metered areas of water distribution systems. Water Resour. Manag. 2014, 28, 683-696. [CrossRef]

23. Arregui, F.; Gavara, F.; Soriano, J.; Pastor-Jabaloyes, L. Performance Analysis of Ageing Single-Jet Water Meters for Measuring Residential Water Consumption. Water 2018, 10, 612. [CrossRef]

24. Arregui, F.; Cabrera, E., Jr.; Cobacho, R. Integrated Water Meter Management; IWA Publishing: London, UK, 2007.

25. Vermersch, M.; Carteado, F.; Rizzo, A.; Johnson, E.; Arregui, F.; Lambert, A. Guidance Notes on Apparent Losses and Water Loss Reduction Planning. 2016. Available online: https://www.mcast.edu.mt/227 (accessed on 7 December 2018).

26. AWWA. Water Audits and Loss Control Programs; AWWA Manual M36 Third Edition; Manual of Water Supply Practices-M36, Water Audits and Loss Control; American Water Works Association: Denver, CO, USA, 2009; ISBN 978-1-58321-631-6.

27. Walski, T.M. Real-World Considerations in Water Distribution System Design. J. Water Resour. Plan. Manag. 2015, 141, 02515002. [CrossRef]

28. Thornton, J. Water Losses Manual, 2nd ed.; McGraw-Hill: New York, NY, USA, 2008.

29. Gonelas, K.; Kanakoudis, V. Reaching economic leakage level through pressure management. Water Sci. Technol. Water Supply 2016. [CrossRef]

30. Kanakoudis, V.; Gonelas, K. Analysis and Calculation of the Short and Long Run Economic Leakage Level in a Water Distribution System. Water Util. J. 2016, 12, 57-66.

31. ISO 4064-2:2014 — Water Meters for Cold Potable Water and Hot Water_Part 2: Test Methods; International Organization for Standardization: Geneve, Switzerland, 2014.

32. Fanner, P.; Thornton, J. The Importance of Real Loss Component Analysis for Determining the Correct Intervention Strategy. In Proceedings of the IWA Leakage Conference 'Leakage 2005', Halifax, NS, Canada, 12-14 September 2005.

33. Yazdandoost, F.; Izadi, A. An asset management approach to optimize water meter replacement. Environ. Model. Softw. 2018, 104, 270-281. [CrossRef]

34. Rizzo, A.; Pearson, D.; Stephenson, M.; Harper, N. Apparent water loss control: A practical approach. Water 2004, 21, 44-45.

35. Fanner, P.; Thornton, J.; Liemberger, R.; Sturm, R. Leakage Management Technologies; AWWA/IWA: Denver, CO, USA; London, UK, 2007.

36. Fanner, P.; Thornton, J.; Liemberger, R.; Sturm, R. Evaluating Water Loss and Planning Loss Reduction Strategies; AWWA/IWA: Denver, CO, USA; London, UK, 2007.

37. AWWA. Near Final Draft for Water Loss Committee Review: AWWA M36 Publication Rewrite; American Water Works Association: Denver, CO, USA, 2006.

38. Morote, Á.-F.; Hernández-Hernández, M. Unauthorised Domestic Water Consumption in the City of Alicante (Spain): A Consideration of Its Causes and Urban Distribution (2005-2017). Water 2018, 10, 851. [CrossRef]

39. Richards, G.L.; Johnson, M.C.; Barfuss, S.L. Apparent losses caused by water meter inaccuracies at ultralow flows. J. Am. Water Works Assoc. 2010, 102, 123-132. [CrossRef]

40. Male, J.W.; Noss, R.R.; Moore, I.C. Identifying and Reducing Losses in Water Distribution Systems; Noyes Publications: Park Ridge, NJ, USA, 1985.

41. Lambert, A.O.; Lalonde, A. Using practical predictions of Economic Intervention Frequency to calculate Short-run Economic Leakage Level, with or without Pressure Management. In Proceedings of the IWA Leakage Conference 'Leakage 2005', Halifax, NS, Canada, 12-14 September 2005.

42. Lambert, A.; Myers, S.; Trow, S. Managing Water Leakage; Financial Times Energy Ltd.: London, UK, 1998.

43. Gavara-Tortes, F.J. Estudio del Comportamiento Metrológico de los Contadores en Abastecimientos de Agua Optimización de su Gestión para la Reducción de las Pérdidas Comerciales. Ph.D. Thesis, Universitat Politècnica de València, Valencia, Spain, 2015. [CrossRef]

(C) 2018 by the authors. Licensee MDPI, Basel, Switzerland. This article is an open access article distributed under the terms and conditions of the Creative Commons Attribution (CC BY) license (http://creativecommons.org/licenses/by/4.0/). 